\title{
Satellite retrieval of cloud base height and geometric thickness of low-level cloud based on CALIPSO
}

\author{
Xin Lu${ }^{1}$, Feiyue Mao ${ }^{1,2,3}$, Daniel Rosenfeld ${ }^{1,4}$, Yannian Zhu ${ }^{5,6}$, Zengxin Pan ${ }^{4}$, and Wei Gong ${ }^{7}$ \\ ${ }^{1}$ State Key Laboratory of Information Engineering in Surveying, Mapping, and Remote Sensing, \\ Wuhan University, Wuhan, 430079, China \\ ${ }^{2}$ School of Remote Sensing and Information Engineering, Wuhan University, Wuhan, 430079, China \\ ${ }^{3}$ Collaborative Innovation Center for Geospatial Technology, Wuhan, 430079, China \\ ${ }^{4}$ Institute of Earth Sciences, The Hebrew University of Jerusalem, Jerusalem, 91904, Israel \\ ${ }^{5}$ School of Atmospheric Sciences, Nanjing University, Nanjing, 210023, China \\ ${ }^{6}$ Joint International Research Laboratory of Atmospheric and Earth System Sciences and Institute for Climate and Global \\ Change Research, Nanjing University, Nanjing, 210023, China \\ ${ }^{7}$ Electronic Information School, Wuhan University, Wuhan, 430072, China
}

Correspondence: Yannian Zhu (yannianzhu@gmail.com)

Received: 5 January 2021 - Discussion started: 18 January 2021

Revised: 18 June 2021 - Accepted: 21 June 2021 - Published: 10 August 2021

\begin{abstract}
Satellite-based cloud base and top height (CBH and $\mathrm{CTH}$ ) and cloud geometrical thickness (CGT) are validated against ground-based lidar measurements and provide new scientific insights. The satellite measurements are done by the Cloud-Aerosol Lidar and Infrared Pathfinder Satellite Observation (CALIPSO). The retrieval methodology is built on the $333 \mathrm{~m}$ resolution low-level water cloud data obtained from the Vertical Feature Mask product of CALIPSO. The methodology is based on the definition that $\mathrm{CBH}$ of boundary layer clouds is the lowest cloud base over an area of several tens of kilometers. This allows taking the $\mathrm{CBH}$ of the neighboring penetrable shallower cloud as having $\mathrm{CBH}$ representative for the entire cloud field. The methodology over the ocean was validated based on observations from two surfacebased ceilometer measurements in the islands of Barbados and the Azores, with an error standard deviation of $\pm 115 \mathrm{~m}$. Validation over land was based on 4 years data of 138 terrestrial ceilometer sites with an error standard deviation of $\pm 220 \mathrm{~m}$. The unprecedented accurate $\mathrm{CBH}$ allows us to obtain CGT, which is an essential parameter in the understanding of the aerosol-cloud interaction. Based on this newly developed methodology, we retrieved the annual, seasonal, and diurnal distributions of global $\mathrm{CBH}, \mathrm{CTH}$, and CGT for two years and analyzed the variations of $\mathrm{CBH}$ and $\mathrm{CTH}$ over the ocean and land. Climatology of the annual mean cloud
\end{abstract}

geometrical properties shows the following. (1) The lowest CBH occurs over the eastern margins of the subtropical oceans and increases westward from 300-400 to 800-900 m. The CGT increases from 300 to $1200 \mathrm{~m}$, respectively. In the western part of the tropical oceans, CBH is $500-600 \mathrm{~m}$ and CGT is $\sim 1500 \mathrm{~m}$. (2) A narrow band of lower CBH and CGT occurs over the Equator, especially over the eastern parts of the oceans. (3) $\mathrm{CBH}$ and CGT over the tropical rain forests (Amazon and Congo) are 1200 and $1500 \mathrm{~m}$, respectively. CBH over the drier tropical land is $1500-2000 \mathrm{~m}$, with CGT of $800-1000$ m. (4) CBH decreases towards Antarctica in the Southern Ocean, while CGT deepens. (5) Seasonally, the mid-latitude global oceans have the lowest CBH (mostly below $500 \mathrm{~m}$ ) and CGT in summer seasons and the highest values in winter. (6) There is just an obvious difference between day and night for the maximum CTH and CGT over the tropics. Over the ocean, there is no discernible difference in $\mathrm{CBH}$, but during night $\mathrm{CTH}$ is higher by $\sim 300 \mathrm{~m}$.

\section{Introduction}

Satellite retrievals of cloud base height $(\mathrm{CBH})$, cloud top height (CTH), and cloud geometrical thickness (CGT) are essential for quantifying cloud dynamic and microphysical 
properties (Rosenfeld et al., 2016; Zhao et al., 2012). Atmospheric aerosols, which serve as cloud condensation nuclei $(\mathrm{CCN})$, control the size and number concentration of cloud droplets and regulate the radiation balance of the Earthatmosphere system (Rosenfeld et al., 2019; Twomey, 1977; Albrecht, 1989; Garrett and Zhao, 2006). Satellite retrieval of $\mathrm{CCN}$ depends on the cloud base updraft (Rosenfeld et al., 2016; Efraim et al., 2020; Zheng, 2019), which is linearly related to CBH (Zheng and Rosenfeld, 2015; Zheng et al., 2020). The cloud base droplet concentration $\left(N_{\mathrm{d}}\right)$ is determined by the cloud base updraft, $\mathrm{CCN}$, supersaturation, wind shear, and so on, which in turn determines the cloud's albedo for a given liquid water path (Twomey, 1974; Sato and Suzuki, 2019). However, the current satellite-retrieved $N_{\mathrm{d}}$ requires the assumption of an adiabatic fraction $\left(f_{\mathrm{ad}}\right)$ of the cloud water, which is usually taken as $f_{\text {ad }}=1$ (Merk et al., 2016; Grosvenor and Wood, 2014). In reality, $f_{\text {ad }}$ is often much smaller than 1 , which leads to a serious underestimation relative to the in situ-measured $N_{\mathrm{d}}$ (Efraim et al., 2020). Accurate information on cloud base and cloud thickness is a necessary condition for retrieval of adiabatic fraction. Therefore, accurate CBH and CGT are extremely important to reduce the uncertainty of aerosol-cloud interaction.

$\mathrm{CBH}$ has practical significance for the aviation community (Noh et al., 2017). Recent studies have shown that CGT can isolate the aerosol-cloud interaction from the influence of meteorology (Rosenfeld et al., 2019; Sato and Suzuki, 2019). $\mathrm{CBH}$ and $\mathrm{CTH}$ are fundamental cloud properties that are required to be parameterized correctly for improving model simulations of climate and climate change (Grosvenor et al., 2017; Zhao and Suzuki, 2019; Lenaerts et al., 2020; Ma et al., 2018). Therefore, it is necessary to obtain the accurate $\mathrm{CBH}$ and $\mathrm{CTH}$ and further retrieve CGT. All these properties are important to understand the complex cloud microphysical processes and aerosol-cloud interaction (Stephens and Webster, 2010; Dupont et al., 2011; Fitch et al., 2016). Low-level clouds reflect most of the incident solar radiation received by the Earth back to space, and they are of great interest for various applications (such as retrieval of cloud microphysical properties, weather prediction, and so on). Therefore, high-precision CBH and CGT data of low-level clouds are the foundation of the follow-up aerosol-cloud interaction research.

Satellites provide a wide range of cloud observations from space (Stephens et al., 2019). It is feasible to retrieve CTH based on satellite data because satellites can observe the cloud top directly (Weisz et al., 2007). Although there is often a large uncertainty in the cloud top heights obtained from passive satellite observations, it is relatively simple to retrieve. In contrast, the retrieval of $\mathrm{CBH}$ is much more challenging but necessary for retrieving CGT. There are already many different methods to retrieve the $\mathrm{CBH}$ based on different satellite observations. The Suomi National Polar-orbiting Partnership (Suomi NPP) Visible Infrared Imaging Radiometer Suite (VIIRS) retrieves CBH based on the CTH and CGT.
However, VIIRS does not directly observe CGT, which is calculated by assuming $f_{\text {ad }}=1$ (Baker, 2011). To investigate the accuracy of VIIRS CBH retrieval algorithm, Seaman et al. (2017) compared the CBH from the VIIRS with those from the CloudSat cloud profile radar. They showed that because the VIIRS official retrieval algorithm is insensitive to upper clouds, the CBH error for all clouds in global is $3.7 \mathrm{~km}$, and even for clouds with accurate $\mathrm{CTH}$, the rootmean-square error (RMSE) of CBH reaches $2.3 \mathrm{~km}$. Böhm et al. (2019) retrieved global CBH data based on multi-angle satellite data, and the validation results based on groundbased observations showed that the RMSE of CBH obtained by this method was $\sim 400 \mathrm{~m}$. Li et al. (2013) conducted the retrieval of global marine boundary layer $\mathrm{CBH}$ based on boundary layer lapse rate observation from the A-train satellite constellation. By comparing their retrieval to CloudSat $\mathrm{CBH}$ retrieval, a standard deviation of $540 \mathrm{~m}$ was found. Zhu et al. (2014) used the imager of the Suomi NPP VIIRS and retrieved the cloud base of convective clouds at an accuracy of $200 \mathrm{~m}$, but this retrieval relied on the strong contrast between the cloud and underlying surface brightness and could not work at night. CloudSat is an essential active cloud radar observation satellite. However, CloudSat has difficulties retrieving the $\mathrm{CBH}$ of low-level clouds for the following reasons. (a) The ground clutter prevents detection of a very low base. (b) Rain from precipitating clouds produces radar returns below cloud base. (c) Due to the dependence of radar reflectivity on the sixth power of the cloud droplet diameter, the reflectivity of clouds with small droplets can be below the CloudSat minimum detectable signal, especially near cloud base where cloud droplets are smallest. It can be seen that these $\mathrm{CBH}$ retrieval methods either have low accuracy or do not provide all-day CBH data. Therefore, there is a yet unfulfilled scientific need to obtain high-precision all-day CGT/CBH based on active satellite observations.

Satellite lidars, such as the Cloud-Aerosol Lidar and Infrared Pathfinder Satellite Observation (CALIPSO), have the potential for accurate retrieval of CBH (Winker et al., 2009). However, CALIPSO typically provides only $\mathrm{CBHs}$ for thin clouds, because it can penetrate only clouds with an optical thickness of less than 5 (Mace and Zhang, 2014). When the thickness of the cloud is sufficient to fully attenuate the CALIPSO lidar signal, CALIPSO cannot provide information about the base of these clouds. Mülmenstädt et al. (2018) retrieved the global CBH using CALIPSO Vertical Feature Mask (VFM) data and evaluated the retrieval algorithm based on ground-based ceilometer observation from about 1500 stations across the continental USA. They extrapolated CBH information from a surrounding field onto profiles for which the lidar signal was attenuated using CALIPSO's VFM and took the mean of all considered VFM CBH retrievals within a distance of $100 \mathrm{~km}$ weighted by estimated uncertainties to determine the $\mathrm{CBH}$ at a given point of interest, but their overall RMSE of CBH exceeded $500 \mathrm{~m}$. This provided the basic idea and motivation to retrieve the $\mathrm{CBH}$ at a higher precision 
in this study. This basic idea is that the $\mathrm{CBH}$ of the optically thin clouds can be used as the CBH for the whole scene at a given range $(\sim 100 \mathrm{~km})$. There are many other challenges. For example, strong surface echoes can affect the identification of cloud bases of CALIPSO observations (Burton et al., 2013). In addition, in aerosol-prone regions, such as East Asia, South Asia, and desert regions, due to the influence of aerosols in the boundary layer, the low-level cloud may be masked by dense aerosol layers, thereby affecting the determination of the cloud layer (Vaughan et al., 2005). Further, large areas of elevated cloud layers can also interfere with the $\mathrm{CBH}$ retrieved by active CALIPSO observations. These factors are expected to result in a large uncertainty in the typical CBH obtained directly based on CALIPSO observations.

To solve the above problems, we derived a new methodology by using the highest resolution of CALIPSO measurements to retrieve the global distribution of $\mathrm{CBH}, \mathrm{CTH}$, and CGT of low-level clouds and validate against in situ ceilometer measurement. The data used in this study are presented in Sect. 2, and the retrieval method is given in Sect. 3. The CALIPSO-retrieved CBHs are evaluated and validated against in situ ceilometer measurements (Sect. 4). Based on the validated CBH, we retrieved CTH and CGT globally and produced global annual, seasonal, and diurnal distribution maps of CBH, CTH, and CGT (Sect. 5). Specific spatial patterns are further discussed in Sect. 6. Conclusions are provided in Sect. 7.

\section{Data}

\subsection{CALIPSO VFM data}

The satellite data analyzed in this study are from the CloudAerosol Lidar with Orthogonal Polarization (CALIOP) lidar on CALIPSO satellite, which can provide two-dimensional (vertical and horizontal along the satellite track) information of clouds with global coverage (Winker et al., 2007). CALIPSO, jointly developed by NASA and CNES, is a sunsynchronous orbiting satellite with an orbital inclination of $98.2^{\circ}$, an orbital altitude of $705 \mathrm{~km}$, a revisit period of 16 days, and an equatorial crossing time of approximately 13:30 local time. The cloud top and base can be obtained from the CALIOP VFM product (Winker et al., 2009). For each CALIOP attenuated backscattering profile, the VFM product identifies features classified as clouds, aerosols, stratospheric features, and surfaces; this is known as feature type. The VFM also provides the thermodynamic phase of cloud layers (water cloud, ice cloud) and the horizontal resolution $(333 \mathrm{~m}$, $1 \mathrm{~km}, 5 \mathrm{~km}, 20 \mathrm{~km}, 80 \mathrm{~km}$ ) that the retrieval was based on. The CALIOP retrieval algorithm must average over a horizontal distance to collect sufficient signal that allows the identification of features on the background noise of atmospheric molecules scattering. The official CALIPSO classification algorithm suffers from the misclassification of clouds and aerosols at low resolution (Mace and Zhang, 2014; Vaughan et al., 2005). In this study, we use VFM version 4.10 data for the full years of 2014 and 2017. The VFM files are available from ASDC (https://eosweb.larc.nasa.gov/, last access: 20 May 2021). To ensure that high-quality CALIPSO VFM data are used, we limit the VFM quality assurance flag to "high" (Mülmenstädt et al., 2018).

\subsection{Ground ceilometer data}

The retrieval algorithm is developed and validated using ground-based ceilometer observations. To represent the different types of low-level clouds around the world, we used ceilometer sites located at different latitudes over the ocean and land (two marine sites and 138 continental sites) respectively to validate the CALIPSO-retrieved $\mathrm{CBH}$. One marine site is at low latitude and one at mid-latitude. The low latitude marine site is Barbados $\left(13.2^{\circ} \mathrm{N}, 59.4^{\circ} \mathrm{W}\right.$ ) (https: //barbados.mpimet.mpg.de/, last access: 17 May 2021). The temporal resolution of the ceilometer at Barbados site is $10 \mathrm{~s}$, and the vertical resolution is $15 \mathrm{~m}$. The mid-latitude marine site is the Eastern North Atlantic (ENA) site located at the Azores $\left(39.1^{\circ} \mathrm{N}, 28.0^{\circ} \mathrm{W}\right)$, operated by the Atmospheric Radiation Measurement (ARM, https://www.arm.gov/data, last access: 17 May 2021). At the ENA site, the ceilometer has a temporal resolution of $16 \mathrm{~s}$, a vertical resolution of $30 \mathrm{~m}$, and a maximum detection range of $7700 \mathrm{~m}$. The data period used in this study of these two marine sites is from January 2017 to December 2017, and the cloud types are mostly marine stratocumulus and trade wind cumulus.

Over land, 138 ceilometer sites are located at the southern Great Plains of the USA. These ceilometer data are derived from Automated Surface Observation System (ASOS). The data source is https://mesonet.agron.iastate.edu/request/ download.phtml (last access: 17 May 2021), which is maintained by Iowa Environmental Mesonet of Iowa State University. The data period used in the validation experiment is from January 2017 to December 2020. The ASOS uses a laser beam ceilometer with a time interval of 5-30 min, with a vertical resolution of $\sim 30 \mathrm{~m}$, and a vertical detection range of $\sim 3700 \mathrm{~m}$. To ensure the data quality of the ASOS ceilometer observations, we only use ceilometer data with cloud base heights less than $3000 \mathrm{~m}$. In our study, ceilometer observations from marine sites were used in the development of the $\mathrm{CBH}$ retrieval algorithm, and data from terrestrial sites were used as independent datasets for the validation and further refinement of the algorithm.

\subsection{Data matching}

Figure 1 illustrates the data matching between CALIPSO and the ceilometer site. To obtain the CALIPSO-retrieved CBH that matches the ceilometer-measured $\mathrm{CBH}$, a scene of $1^{\circ}$ along the CALIPSO track is selected (the gray shaded area in Fig. 1), centered in time on the overpass time and extending 


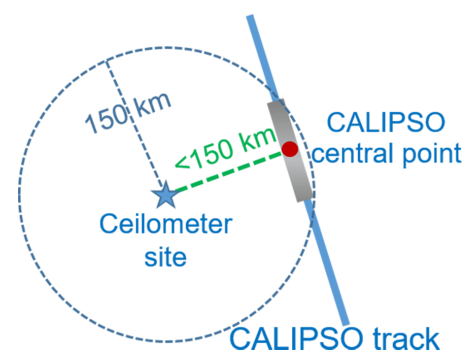

Figure 1. Schematic of matching between the CALIPSO and a marine ceilometer observation site. The blue star indicates the location of the ceilometer site, the blue solid line is the CALIPSO track, the red solid circle represents the CALIPSO central point, the dashed green line represents the shortest distance from the ceilometer site to the CALIPSO central point, and the gray shaded area is the $1^{\circ}$ CALIPSO scene. The blue circle is centered on the ceilometer site and has a radius of $150 \mathrm{~km}$.

$0.5^{\circ}$ to the backward and forward along the CALIPSO track. The scene is selected if the distance from the CALIPSO center point to the ceilometer site is less than $150 \mathrm{~km}$ and is used for matching CALIPSO with the ceilometer data. Then we obtained the distribution of the base height of cloud features observed by ceilometers within $30 \mathrm{~min}$ before and after the CALIPSO overpass time $\left(\mathrm{CB}_{\text {ceilo }}\right)$. To avoid the underestimation of low CBHs and overestimation of high CBHs by the ceilometer due to the influence of developing higher-level clouds and ceilometer measurement noise, the lowest $10 \%$ quantile of the $\mathrm{CB}_{\text {ceilo }}$ is determined as true $\mathrm{CBH}$ (Wang et al., 2018).

The retrieval methodology in this study relies on the assumption of the undisturbed boundary layer with a similar cloud base height within the scene. The topography of the islands at the Azores has volcanic peaks with heights up to $500 \mathrm{~m}$ and may violate the homogeneity assumption. To avoid the anomalous uplift of clouds by the topography of these adjacent islands, we restricted the CALIPSO data according to the terrain and wind directions as shown in Fig. A1. If the elevation corresponding to the CALIPSO data matching the ENA site ceilometer data is higher than $30 \mathrm{~m}$, the CALIPSO data are rejected. Similarly, to avoid the situation that the clouds that traveled above the adjacent islands were perturbed, we rejected the CALIPSO data with the wind direction of southwest/southeast if the CALIPSO track is located at the east/west ocean of ENA site (Fig. A1a and $b)$. The wind direction is from the meteorological observation data of ENA site, and the elevation data are from the CALIPSO VFM product.

\section{CALIPSO CGT retrieval algorithm}

The objective of the $\mathrm{CBH}$ retrieval is to retrieve the forming level of clouds. In the case of a well-mixed boundary layer, it is the lifting condensation level. When clouds are decoupled, that level is usually higher. That formative cloud base level is similar in areas with similar thermodynamic structure, which is conducive to a nearly constant cloud base height. Thus, the CBH of optically thicker clouds that cannot be penetrated by CALIOP can be expressed by the $\mathrm{CBH}$ of the surrounding penetrable thin clouds. The retrieval algorithm relies on this assumption, by adopting the lowest reliably detected cloud height along a CALIPSO track of approximately $100 \mathrm{~km}\left(1^{\circ}\right.$ along the track) as the cloud base height.

\subsection{Extraction of $\mathbf{3 3 3} \mathbf{m}$ horizontal resolution low-level cloud feature}

In this study, we retrieve CBH and CGT for CALIPSO VFM scenes which are identified as low-level water clouds. Low clouds are defined following the International Satellite Cloud Climatology Project as clouds distributed below $680 \mathrm{hPa}$ (Hahn et al., 2001), which also complies with the detection range of the ceilometer. Figure 2 displays an example of CALIPSO low-level cloud feature determination. For each $1^{\circ}$ scene along the CALIPSO track, the distribution of the low-level water clouds which had sufficient signal to be detected with a horizontal resolution of $333 \mathrm{~m}$ (light blue areas in Fig. 2c) was obtained. These cloud features were identified based on the CALIPSO feature type data (Fig. 2a) and resolution data (Fig. 2b). Then, based on the low-level cloud information in Fig. 2c, we could retrieve the $\mathrm{CBH}, \mathrm{CTH}$, and CGT of this scene.

Using $333 \mathrm{~m}$ resolution cloud feature information allows a better separation between the clouds and boundary layer aerosols, because the aerosol identification is based mostly on $1 \mathrm{~km}$ or lower-resolution data, as evident in Fig. 2b (Vaughan et al., 2005). Moreover, CBH obtained from higher-resolution VFM data (such as $333 \mathrm{~m}$ resolution) was closer to the lifting condensation level (Ham et al., 2017). Also, low horizontal resolution is most likely to lead to false detection of clouds (Mace and Zhang, 2014). Therefore, it is more reliable to use the water cloud information with the highest resolution of $333 \mathrm{~m}$ to retrieve the $\mathrm{CBH}$ of low-level clouds compared to previous studies based on coarse-spatialresolution CALIPSO satellite data. Thus, we chose to use $333 \mathrm{~m}$ resolution instead of other resolutions for $\mathrm{CBH}$ and CGT retrieval. This is one of the main differences between our algorithm and other current algorithms, such as Mülmenstädt et al. (2018). This largely reduces the impact on $\mathrm{CBH}$ retrieval due to official algorithmic misclassification of aerosols and clouds in low-resolution CALIPSO VFM data.

\subsection{CALIPSO initial $\mathrm{CBH}$ in $1^{\circ}$ scene}

For each $1^{\circ}$ scene along the CALIPSO track, based on $333 \mathrm{~m}$ horizontal resolution low-level cloud information as described in Sect. 3.1, we obtained the height distribution of the lowest cloud feature $\left(H_{\min }\right)$ of each water cloud profile under which the surface is detectable as shown in Fig. 3a. 


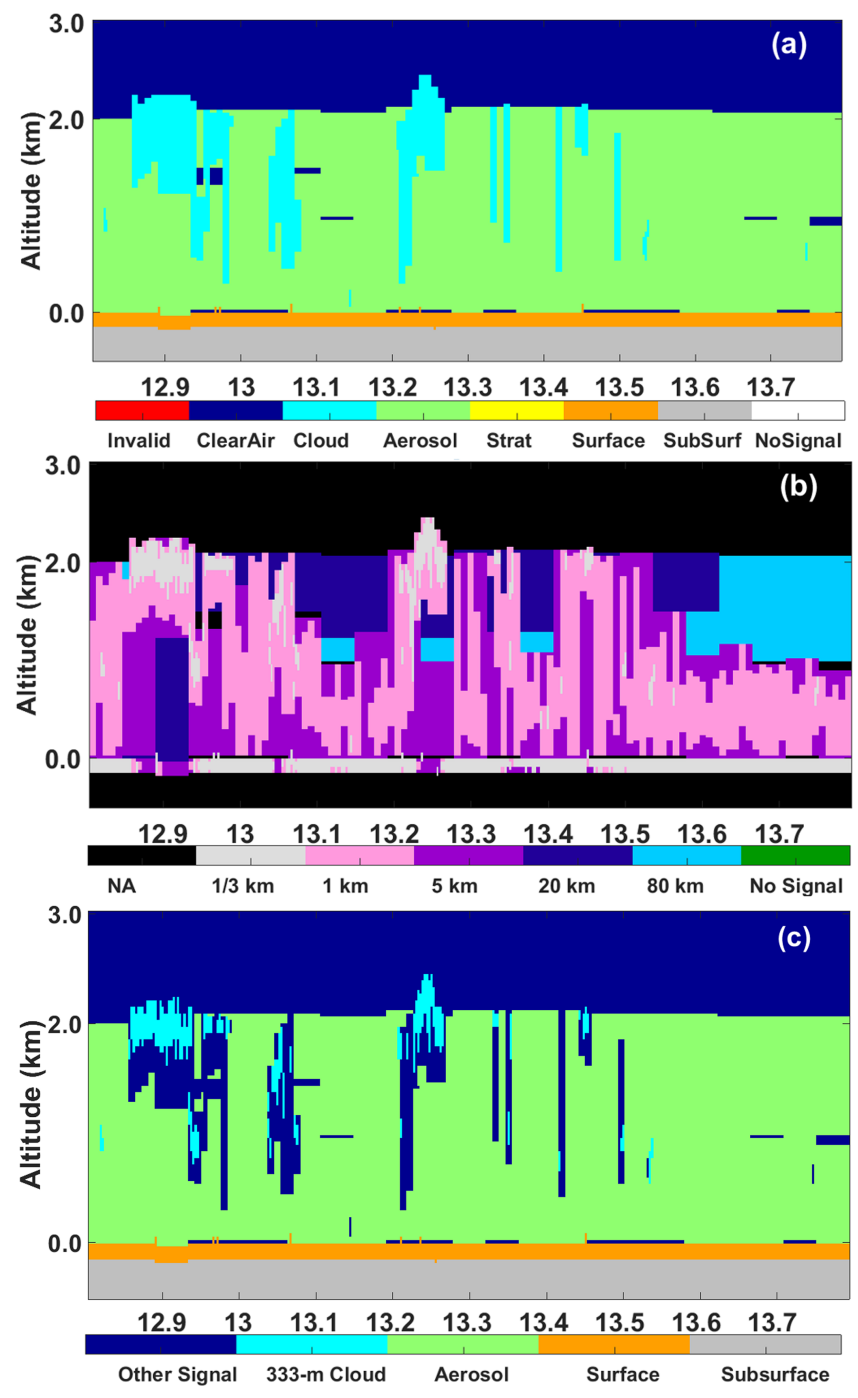

Figure 2. Schematic of CALIPSO low-level cloud feature determination (CALIPSO VFM data at 05:51:17 UTC on 3 January 2017). (a) Latitude-altitude distribution of feature type based on CALIPSO VFM feature type parameter; the light blue areas represent the water cloud features. "Strat" is the stratospheric feature; "SubSurf" is the subsurface. (b) Resolution information distribution based on CALIPSO VFM resolution parameter; the gray areas represent the $333 \mathrm{~m}$ resolution features. (c) The $333 \mathrm{~m}$ horizontal resolution water cloud distribution combined by panels (a) and (b); the light blue areas indicate the $333 \mathrm{~m}$ horizontal resolution water clouds, the green areas refer to aerosols at any resolution, and the orange area is the surface.

Then, based on this $H_{\min }$ data, we obtained the $10 \%$ quantile of the $H_{\min }$ distribution for each $1^{\circ}$ scene as shown in Fig. 3b, which will be used to reduce the interference of strong surface signals and thick aerosols.

Extremely low $H_{\min }$ are more prone to misclassification because the mixture of surface signals and cloud features or VFM misclassified near-surface thick aerosols as clouds (Burton et al., 2013; Vaughan et al., 2005), and the lowest height of $H_{\min }$ cannot be used as the initial CBH of this $1^{\circ}$ scene. To obtain the optimal quantile of the initial $\mathrm{CBH}$, we carried out a sensitivity test based on the CALIPSO-retrieved $\mathrm{CBH}$ and the ceilometer-measured $\mathrm{CBH}$ from two ground marine observation stations (Barbados site and ENA site) in 2017 as shown in Fig. 4. The sensitivity test shows that the application of CALIPSO $H_{\min }$ at $10 \%$ quantile as the initial $\mathrm{CBH}$ of this $1^{\circ}$ scene greatly reduces the problem that the lowest $H_{\min }$ retrieved from CALIPSO is much smaller than the true $\mathrm{CBH}$ (RMSE reduced by $88 \mathrm{~m}$ ). Using $H_{\min }$ at $10 \%$ quantile as the initial $\mathrm{CBH}$, rather than simply calculating the average $\mathrm{CBH}$ of $H_{\min }$ as the initial value, goes some way to reducing the effect of high-altitude spreading of water clouds due to convective activity on the retrieval of CBHs.

\subsection{Determination of CALIPSO CBH, CTH, and CGT of $1^{\circ}$ scenes}

After getting the initial $\mathrm{CBH}\left(H_{\min }\right.$ at $10 \%$ quantile), there are still many factors affecting the determination of the final $\mathrm{CBH}$ in the cloud scenes that contribute to the uncertainty or add limitations to the $\mathrm{CBH}$ retrieval. There are many confounding factors, including multilayer cloud fraction $\left(F_{\text {multi }}\right)$ and detection efficiency of CALIOP lidar $\left(E_{\text {lidar }}\right.$ and $\left.E_{\text {lidar_full }}\right)$. These difficulties are overcome by the added selection criteria, which are tested against in situ ceilometer measurements as presented in the following subsections.

\subsubsection{Multilayer clouds}

Multilayer status of features can be detected by CALIPSO vertical profile measurements. In VFM data, for each profile (from the surface to the altitude of $20 \mathrm{~km}$ ), if cloud features are continuous, then it is a profile with a single-layer cloud; if there is more than one cloud segment in that vertical profile, then this profile contains multilayer clouds. In this study, for each $1^{\circ}$ CALIPSO scene, only profiles containing continuous single-layer clouds are used to retrieve $\mathrm{CBH}, \mathrm{CTH}$, and their thickness; that is, any profile with multilayer clouds is excluded. This is because the aerosol-cloud interaction studies mainly focus on single-layer clouds. Therefore, when there are too many multilayer clouds in a $1^{\circ}$ scene, in order to guarantee the effectiveness of $\mathrm{CBH}$ retrieval, this scene will be rejected. We use the $F_{\text {multi }}$ to represent the cloud cover of the multilayer clouds in the scene. For a given $1^{\circ}$ CALIPSO scene, $F_{\text {multi }}$ is calculated using Eq. (1):

$F_{\text {multi }}=N_{\text {multi }} / N_{\text {total }}$

where $N_{\text {multi }}$ is the number of the CALIPSO lidar profiles that contain multilayer clouds, and $N_{\text {total }}$ is the total number of the CALIPSO lidar profiles collected in a given $1^{\circ}$ CALIPSO scene. In order to obtain the optimal threshold of $F_{\text {multi }}$, we carried out the sensitivity test as displayed in Fig. 5. It can be seen from Fig. 5 that when the multilayer cloud fraction limitation is used, the RMSE decreases from 

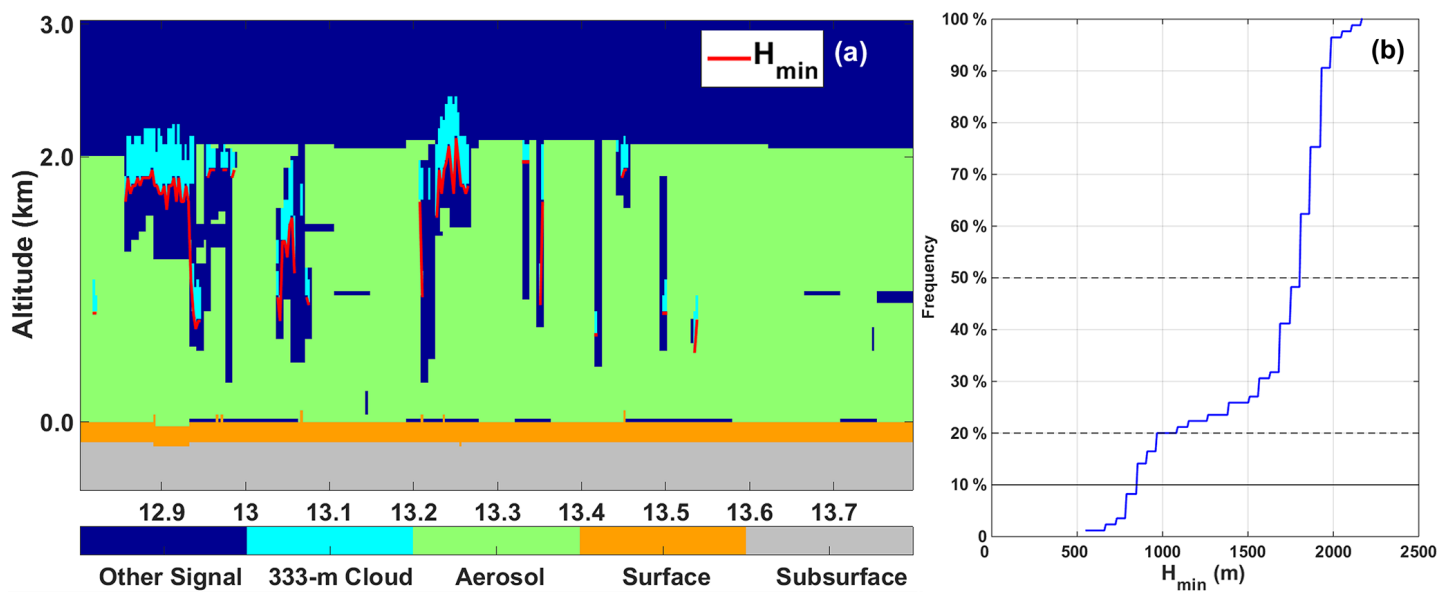

Figure 3. (a) The same as Fig. 2c but with the distribution of $H_{\min }$ (the red line). (b) Cumulative distribution of the $H_{\mathrm{min}}$ at any quantile for the scene in panel (a) (The black solid line represents the $H_{\min }$ at the $10 \%$ quantile, which will be used to reduce the interference of strong surface signals and thick aerosols. The black dotted lines represent the $H_{\min }$ at the $20 \%$ and $50 \%$ quantile, respectively.).

$325 \mathrm{~m}$ in Fig. $4 \mathrm{~b}$ to $\sim 225 \mathrm{~m}$. Given there are a considerable amount of multilayer clouds on the globe, we chose a moderate multilayer cloud fraction threshold of $40 \%$. Therefore, when there are too many multilayer clouds in a scene $\left(F_{\text {multi }}>40 \%\right)$, the scene is rejected.

\subsubsection{Penetration efficiency of CALIOP}

When the clouds are sufficiently thick, CALIOP lidar beam cannot penetrate them and reach the surface. Although we can use the cloud base information of thin clouds as a proxy for the cloud base of optically thicker clouds within the field, we still need to consider the penetration efficiency of CALIPSO to thick clouds. The fraction of cloudy pixels in which the lidar penetrates the clouds to their base is defined as lidar penetration efficiency ( $E_{\text {lidar }}$ and $\left.E_{\text {lidar_full }}\right) . E_{\text {lidar }}$ is used to determine the lowest penetration efficiency that can still provide valid cloud base information of $333 \mathrm{~m}$ resolution cloud in this study, which is calculated using Eq. (2):

$E_{\text {lidar }}=N_{\text {surface_333 }} / N_{\text {total_333, }}$

where $N_{\text {surface_} 333}$ refers to the number of CALIPSO lidar profiles that have both $333 \mathrm{~m}$ horizontal resolution clouds and a detectable surface, and $N_{\text {total_}} 333$ is the total number of CALIPSO lidar profiles that detected the $333 \mathrm{~m}$ horizontal resolution clouds. The sensitivity test result of $E_{\text {lidar }}$ is displayed in Fig. 6. We can see that the higher $E_{\text {lidar }}$ the better cloud base height retrieval we can get, but when $E_{\text {lidar }}$ approaches 1 we lose the ability of detecting CBH of optically thick clouds. Therefore, an optimal $E_{\text {lidar }}$ of $50 \%$ was chosen. That is, when the $E_{\text {lidar }}<50 \%$ in a scene, in order to guarantee the effectiveness of $\mathrm{CBH}$ retrieval, the scene is rejected.

In addition, the penetration efficiency of full-resolution clouds is also taken into consideration, which is calculated using Eq. (3):

$E_{\text {lidar_full }}=N_{\text {surface_fullCloud }} / N_{\text {total_fullCloud }}$,

where $N_{\text {surface_fullCloud }}$ refers to the number of CALIPSO lidar profiles that have both full-resolution clouds and a detectable surface; $N_{\text {total_fullCloud }}$ is the total number of CALIPSO lidar profiles that detected the full-resolution clouds. The sensitivity test result of $E_{\text {lidar_full }}$ is displayed in Fig. 7 . We can see that the higher $E_{\text {lidar_full }}$ the better cloud base height retrieval we can get, but when $E_{\text {lidar_full }}$ is greater than $50 \%$, the amount of matched data is significantly reduced, and the ability to retrieval high $\mathrm{CBH}$ is lost. Therefore, an optimal $E_{\text {lidar_full }}$ of $50 \%$ was chosen.

Therefore, after we obtained the initial $\mathrm{CBH}\left(H_{\min }\right.$ at $10 \%$ quantile), we reject a $1^{\circ}$ CALIPSO scene when

a. the multilayer cloud fraction of this scene is greater than $40 \%\left(F_{\text {multi }}>40 \%\right)$

b. penetration efficiency of CALIOP lidar of $333 \mathrm{~m}$ horizontal resolution cloud features is less than $50 \%$ $\left(E_{\text {lidar }}<50 \%\right)$, and

c. penetration efficiency of CALIOP lidar of fullresolution cloud features is less than $50 \%$ $\left(E_{\text {lidar_full }}<50 \%\right)$.

After the above processing, we obtained the final $\mathrm{CBH}$ of that CALIPSO $1^{\circ}$ scene. This cloud base height information is mainly extracted from broken or thin boundary layer clouds. Then $333 \mathrm{~m}$ resolution cloud information as described in Sect. 3.1 was applied to retrieve the CTH of these scenes. For all water cloud layers with a resolution of $333 \mathrm{~m}$, when the $\mathrm{CBH}$ of low-level clouds is retrieved, we obtain the cloud top height of all $333 \mathrm{~m}$ cloud profiles $\left(H_{\max }\right)$ in this scene and take the mean height of the highest $10 \%$ quantile of $H_{\max }$ as 

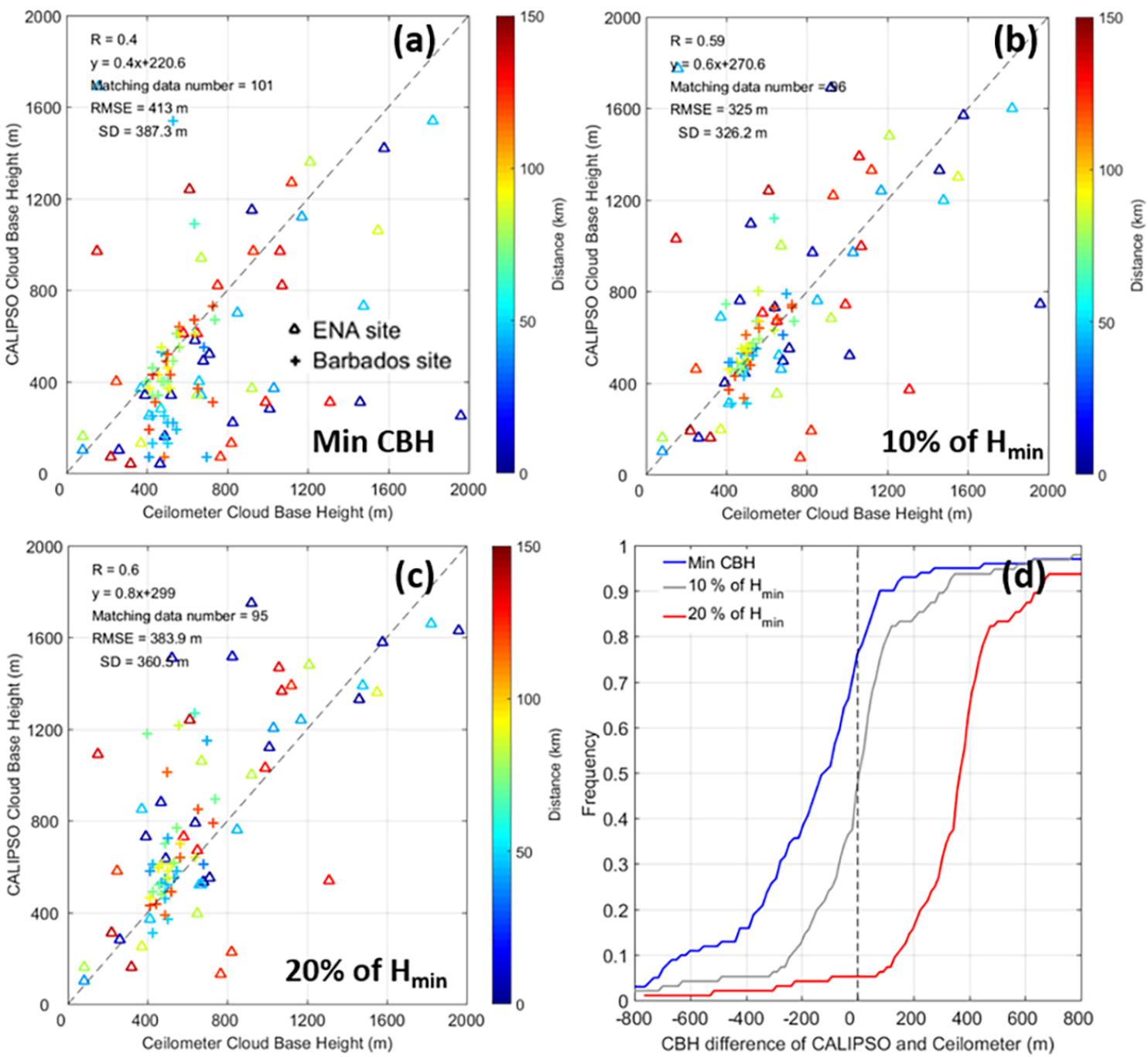

Figure 4. (a) Scatter plot of CALIPSO CBH (the minimum CBH for each $1^{\circ}$ scene) and ceilometer CBH at two marine sites in 2017. The triangle represents the data for the ENA site, and the crosses represent the data for the Barbados site. The color represents the shortest distance from the CALIPSO ground track to the ceilometer site. $R$ is the Pearson correlation coefficient, $y$ indicates the linear fitting relationship between ceilometer $\mathrm{CBH}$ and CALIPSO CBH, matching data number is the data amount of the scatter plot, RMSE is the root-mean-square error, and SD is the standard deviation. Panels (b) and (c) are the same as panel (a) but for CALIPSO CBH at $10 \%$ quantile of $H_{\min }$ and $20 \%$ quantile of $H_{\min }$, respectively. (d) Cumulative distribution of the difference between CALIPSO CBH and ceilometer CBH at two sites in 2017.

the CTH of that scene according to the definition in Zhu et al. (2018). Finally, the CGT of this $1^{\circ}$ scene is the difference between CTH and CBH (Scheirer and Macke, 2003).

\section{Evaluation of CALIPSO-retrieved CBH}

\subsection{Over the ocean}

In this study, we used ceilometer-measured CBH data from two ground observation stations at oceanic sites at low latitude and midlatitude (Barbados site and ENA site) in 2017 to obtain sufficient data for the development of CALIPSO $\mathrm{CBH}$ retrieval. Finally, 67 sets of matching cases were ob- tained in 2017, including 20 matching cases for ENA site and 47 for Barbados site (Fig. 7b). The statistical analysis of these matching cases shows that the CALIPSO-retrieved $\mathrm{CBH}$ has a good consistency with the $\mathrm{CBH}$ observed by the ceilometers at these two observation stations. The $R$ is 0.88 , the RMSE is only $116.3 \mathrm{~m}$, and the standard deviation (SD) is $116.6 \mathrm{~m}$. Due to the restrictions of terrain and wind directions for CALIPSO scenes in ENA site as described in Sect. 2.2, the ENA site matches fewer cases than the Barbados site in 2017. The cumulative distribution of the CBH difference between CALIPSO and ceilometer in Fig. 7d (the gray line) indicates that $\sim 70 \%$ of the matching cases have a deviation of less than $100 \mathrm{~m}$. It can also be seen from Fig. $7 \mathrm{~b}$ (the color 

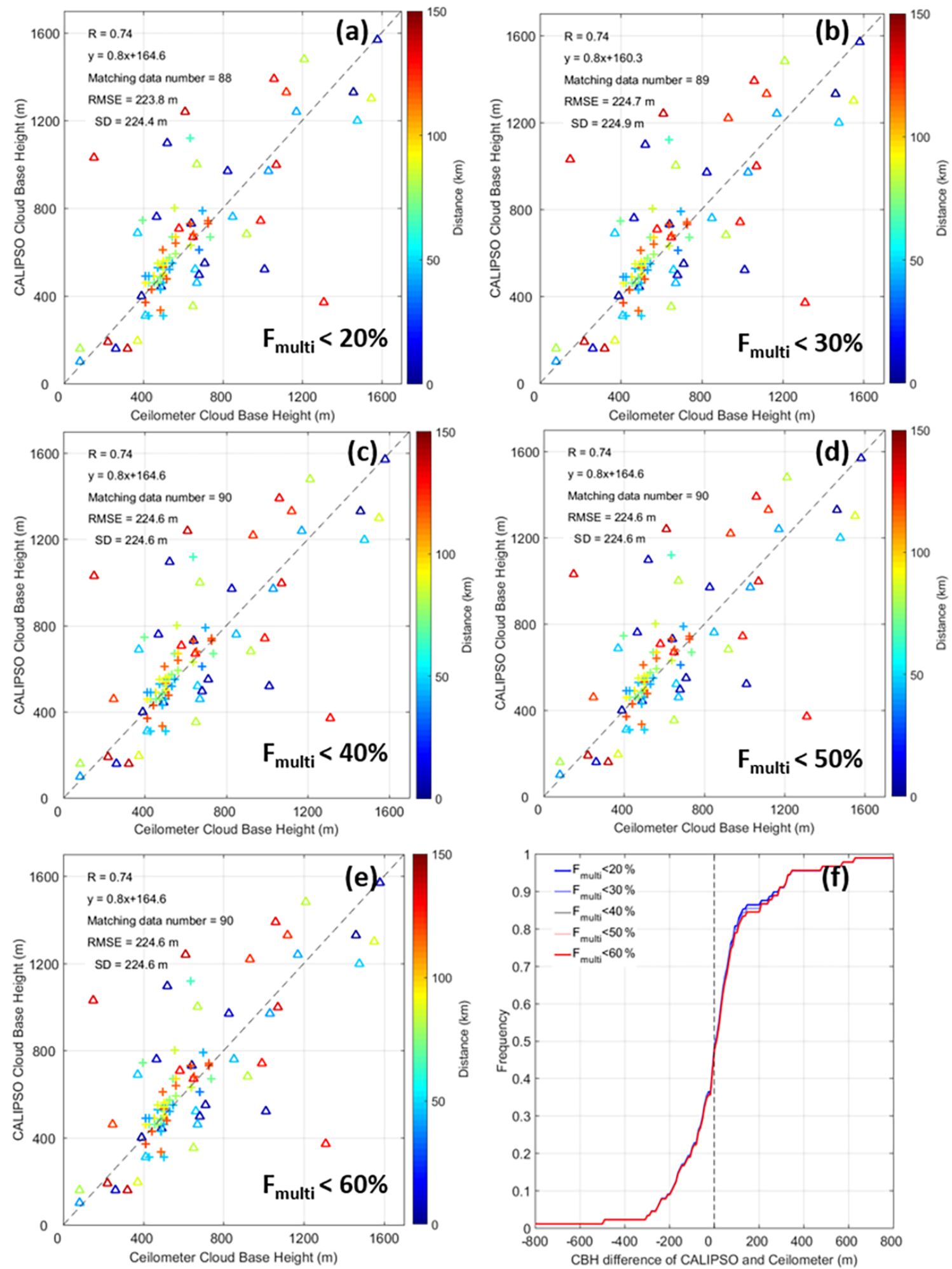

Figure 5. (a) Scatter plot of CALIPSO CBH and ceilometer-measured CBH at two marine sites in 2017, when selecting scenes with multilayer cloud fraction $\left(F_{\text {multi }}\right)<20 \%$. The triangle represents the data for the ENA site, and the crosses represent the data for the Barbados site. The color represents the shortest distance from the CALIPSO ground track to the ceilometer site. Panels (b), (c), (d), and (e) are the same as panel (a), but the selection criteria of $F_{\text {multi }}$ in panel (b) are less than $30 \%$, in panel (c) they are is less than $40 \%$, in panel (d) they are less than $50 \%$, and in panel (e) they are less than $60 \%$, respectively. (f) Cumulative distribution of the difference between CALIPSO $\mathrm{CBH}$ and ceilometer $\mathrm{CBH}$ at two sites in 2017. Different colored lines represent the cumulative distribution at different selection criteria of $F_{\text {multi }}$. 

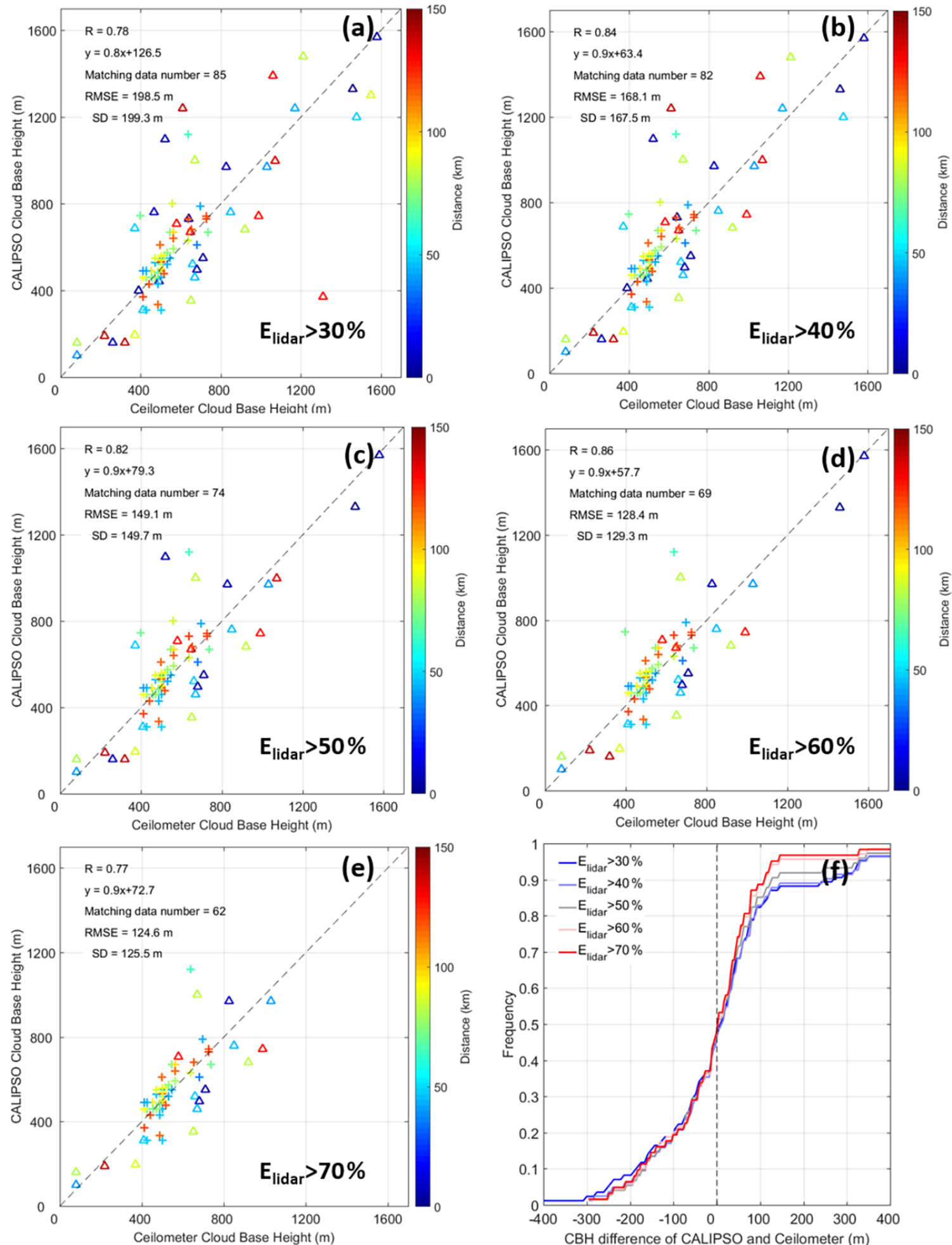

Figure 6. (a) Same as Fig. 5 but for selecting scenes with penetration efficiency of $333 \mathrm{~m}$ horizontal resolution cloud features $\left(E_{\text {lidar }}\right)>30 \%$. The selection criteria of multilayer cloud fraction are the same as Fig. 5c. The triangle represents the data for the ENA site, and the crosses represent the data for the Barbados site. The color represents the shortest distance from the CALIPSO ground track to the ceilometer site. Panels (b), (c), (d), and (e) are the same as panel (a), but the selection criteria of $E_{\text {lidar }}$ in panel (b) are larger than $40 \%$, in panel (c) they are larger than $50 \%$, in panel (d) they are larger than $60 \%$, and in panel (e) they are larger than $70 \%$, respectively. (f) Cumulative distribution of the difference between CALIPSO CBH and ceilometer CBH at two sites in 2017. Different colored lines represent the cumulative distribution at different selection criteria of $E_{\text {lidar }}$. 

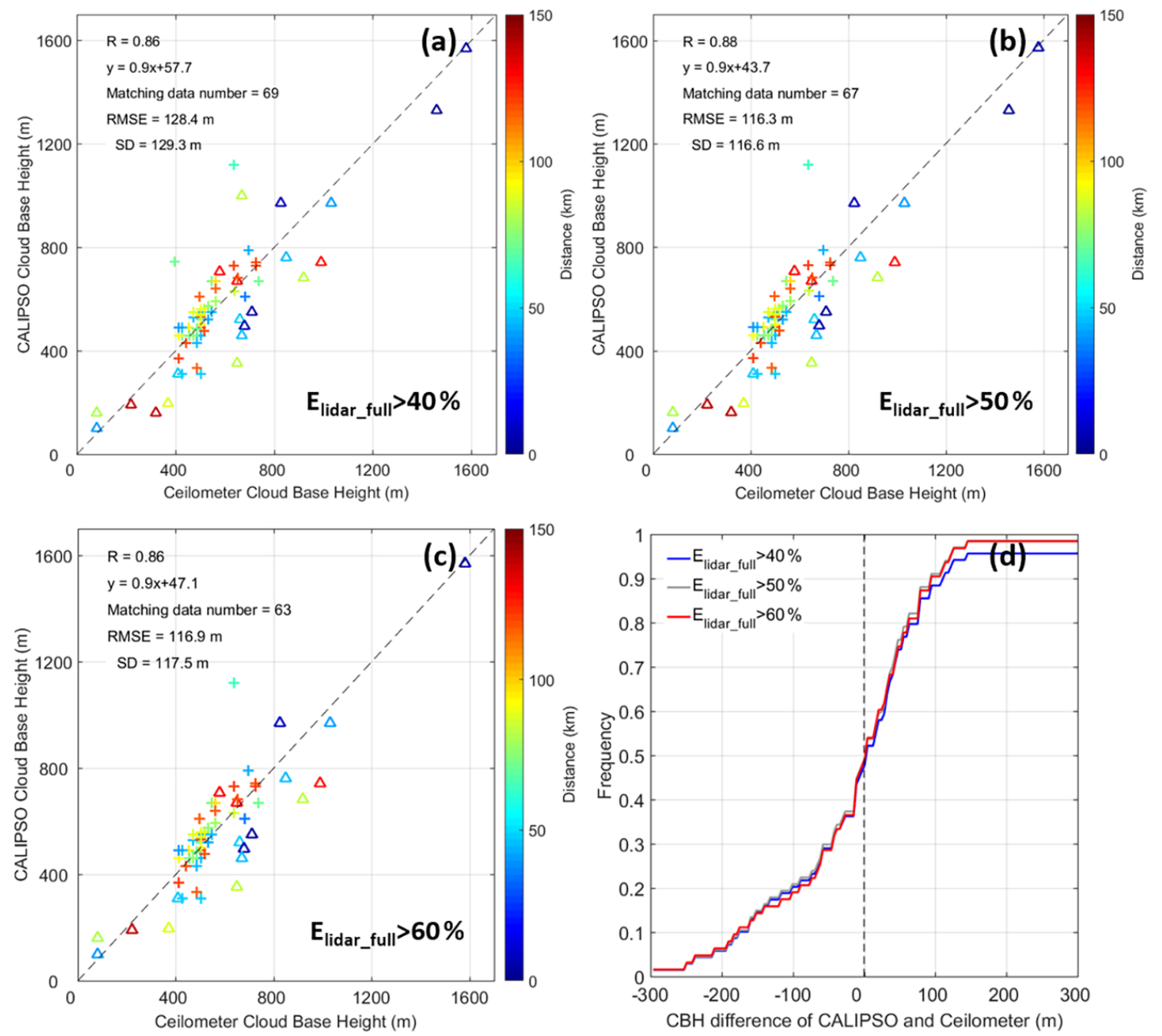

Figure 7. Same as Fig. 5 but (a) when penetration efficiency of full-resolution cloud features ( $\left.E_{\text {lidar_full }}\right)$ of one scene is larger than $40 \%$; selection criteria of multilayer cloud fraction and penetration efficiency of $333 \mathrm{~m}$ resolution cloud are the same as Fig. $6 \mathrm{c}$ at two marine sites in 2017. The triangle represents the data for the ENA site, and the crosses represent the data for the Barbados site. The color represents the shortest distance from the CALIPSO ground track to the ceilometer site. Panels (b) and (c) are the same as panel (a), but the selection criteria

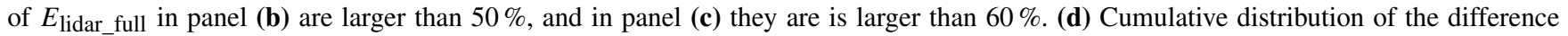
between CALIPSO CBH and ceilometer CBH at two sites in 2017. Different colored lines represent the cumulative distribution at different selection criteria of $E_{\text {lidar_full. }}$.

represents the distance from the CALIPSO ground track to the ceilometer site) that over the ocean, when the distance is less than $150 \mathrm{~km}$, the deviation between CALIPSO-retrieved $\mathrm{CBH}$ and ceilometer $\mathrm{CBH}$ has little to do with the distance.

\subsection{Over land}

To validate the applicability over land of the $\mathrm{CBH}$ retrieval algorithm, we conducted additional validation experiments using 4 years of continental ceilometer data from 138 sites in the southern Great Plains of the USA (as shown in Fig. A2). The data period is taken from 2017 to 2020 because during this period the ceilometers provide better time resolution of cloud base measurements. Since the cloud base is not as homogeneous over land as over the ocean, we consider using the cloud information below the first peak nearest to the surface in the cloud fraction profile of $1^{\circ}$ scenes as a proxy for all cloud base information in this scene (which we defined as the first local peak above the surface). In this way, we avoid missing the newly developed clouds with small sizes. Therefore instead of using $H_{\min }$ at $10 \%$ quantile of all clouds as the initial CBH over the ocean, we tested the $\mathrm{CBH}$ at different quartiles of the first local peak as the initial $\mathrm{CBH}$ for the scene (detailed information is provided in Table B1 in the Appendix). The results show that there is a shallow minimum RMSE when the initial CALIPSO CBH is 
at the $40 \%$ quantile of the first local peak which closest to surface. Thus on land, the CALIPSO-retrieved initial CBH is $40 \%$ quantile of the first local peak, while over the ocean it is $H_{\min }$ at $10 \%$ quantile. Then, based on the $\mathrm{CBH}$ data obtained from the above processing, we further tested the effects of $F_{\text {multi }}, E_{\text {lidar }}$, and $F_{\text {lidar_full }}$ over land following the same process as over the ocean, as shown in Fig. A3 in the Appendix. From the results, it can be seen that the optimal thresholds for these parameters $\left(F_{\text {multi }}<40 \%, E_{\text {lidar }}>50 \%\right.$, and $F_{\text {lidar_full }}>50 \%$ ) on land are consistent with those over the ocean, which also shows that the $\mathrm{CBH}$ retrieval algorithm we developed based on cloud observations from the ocean is applicable on land. These final criteria for CALIPSO CBH retrieval used over the ocean and land are also summarized in Table B2.

As mentioned before due to the complexity of topography and land surface situation, the cloud base height varies at larger spatial scales. The $150 \mathrm{~km}$ distance between the shortest distance from the CALIPSO ground track to the ceilometer site cannot be used for over-land validation. We have to shrink the distance to minimize the spatial variability due to the changes over land. We tested the effect of distance (that is the shortest distance from the CALIPSO ground track to the ceilometer site) and observation time on the retrieval results (Fig. A4 in the Appendix). The results (Fig. A4b) show that the absolute error between the CALIPSO CBH and the ceilometer $\mathrm{CBH}$ becomes smaller as the distance decreases and stabilizes at distances less than $50 \mathrm{~km}$. It is therefore preferable to limit the distance to $50 \mathrm{~km}$ for studies on land to better meet the assumptions of a homogeneous CBH within the scene. It can also be seen that the cloud base heights are more evenly distributed during the daytime (Fig. A4a, $300-1800 \mathrm{~m}$ ) than at night, while at night CBHs are mainly concentrated below about $700 \mathrm{~m}$. In addition to the distance limitation, the cloud base homogeneity is further constrained by comparing the lifted condensation level $\left(H_{\mathrm{LCL}}\right)$ to the ceilometer cloud base height. To satisfy the cloud base homogeneity assumption (Efraim et al., 2020), cases are selected when the absolute difference between the $H_{\mathrm{LCL}}$ (calculated from ASOS-observed air temperature and dew point temperature) and ceilometer CBH is less than 200. In summary, the ceilometer measurements over land need to satisfy the following conditions for validating CALIPSO CBH retrieval: (1) the ceilometer is within $50 \mathrm{~km}$ radius to the center of CALIPSO ground track; (2) the ceilometer-measured CBH should have an absolute difference less than $200 \mathrm{~m}$ against $H_{\mathrm{LCL}}$ as calculated from the surface measured air temperature and dew point.

Ceilometer data that passed these conditions were used for validating the CALIPSO-retrieved cloud base height. Figure 8 shows the final verification results over land. Based on 4 years of observations from 138 ceilometer sites in the southern Great Plains, 733 sets of matching cases were obtained in 2017-2020 (daytime: 469 sets; nighttime: 264 sets). The statistical analysis of these matching cases (Fig. 8a) shows that the CALIPSO-retrieved CBH has a good consistency with the $\mathrm{CBH}$ observed by the ceilometers at these continental sites. The $R$ is 0.92 , the RMSE is $217.2 \mathrm{~m}$, and the standard deviation is $217.1 \mathrm{~m}$. The cumulative distribution of the CBH difference between CALIPSO and ceilometer in Fig. 8b indicates that $\sim 70 \%$ of the matching cases have a deviation of less than $200 \mathrm{~m}$. In addition, the daytime results $(R=0.92, \mathrm{RMSE}=178.0 \mathrm{~m})$ are better than the nighttime results $(R=0.27$, RMSE $=273.3 \mathrm{~m})$. From Fig. $8 \mathrm{e}$ it can be observed that the $\mathrm{CBH}$ at night is mainly concentrated below $800 \mathrm{~m}$. This might be due to the effect of low-level clouds and fog patches, which possibly contaminate the ceilometer data. Therefore, it is unreasonable to validate the CALIPSO retrieval against the nighttime ceilometer measurements, and daytime data are more suitable for validation.

\section{Global distributions}

\subsection{Overall distributions}

Based on the above retrieval methodology, we further obtained the global geographic distribution of 2-year mean $\mathrm{CBH}, \mathrm{CTH}$, and CGT on $2^{\circ} \times 2^{\circ}$ latitude-longitude grids in 2014 and 2017 (Fig. 9). The CALIPSO CBH retrieval domain over land is $50 \mathrm{~km}$, and over the ocean it is $100 \mathrm{~km}$ along the CALIPSO track. To ensure the validity of the retrieval results, we only use the data at a $2^{\circ}$ grid when there are more than 20 valid scenes on this grid, among which the valid scenes indicate that we have retrieved the $\mathrm{CBH}$, $\mathrm{CTH}$, and CGT based on the $333 \mathrm{~m}$ resolution cloud data. The blanks in the geographic distribution are mainly due to the lack of valid scenes for a given grid. This is more frequent over land than over the ocean, because there are more scenes with cloud bases above $3 \mathrm{~km}$ or more cloud-free scenes (e.g. Sahara, Australia).

The distribution of $\mathrm{CBH}$ above ground level (Fig. 9a) shows that over land, CBHs are higher than over the ocean. In the oceanic area, the cloud bases are higher in the midlatitudes than at the equatorial regions and at high latitudes, which are in good agreement with Mülmenstädt et al. (2018). In addition, in the mid-latitudes, the lowest cloud bases are mostly concentrated in offshore areas (Böhm et al., 2019), which are mainly less than $400 \mathrm{~m}$. Clouds with high CTHs occur mainly over the ocean at low and high latitudes and over the land area, with CTHs over $2000 \mathrm{~m}$, which is consistent with the CTH result of Sun-Mack et al. (2014). In particular, there is a peak area of CTH in the Tibetan Plateau region, essentially greater than $2800 \mathrm{~m}$, which is consistent with the conclusions obtained by Yang et al. (2020) based on high-spatial-resolution Himawari imager data. Similar to the distribution of the $\mathrm{CBH}$, the lowest $\mathrm{CTH}$ which are mainly $\sim 1000 \mathrm{~m}$ are also concentrated in offshore regions and the equatorial regions of the western hemisphere, in agreement with Zuidema et al. (2009). Thus, shallow clouds 

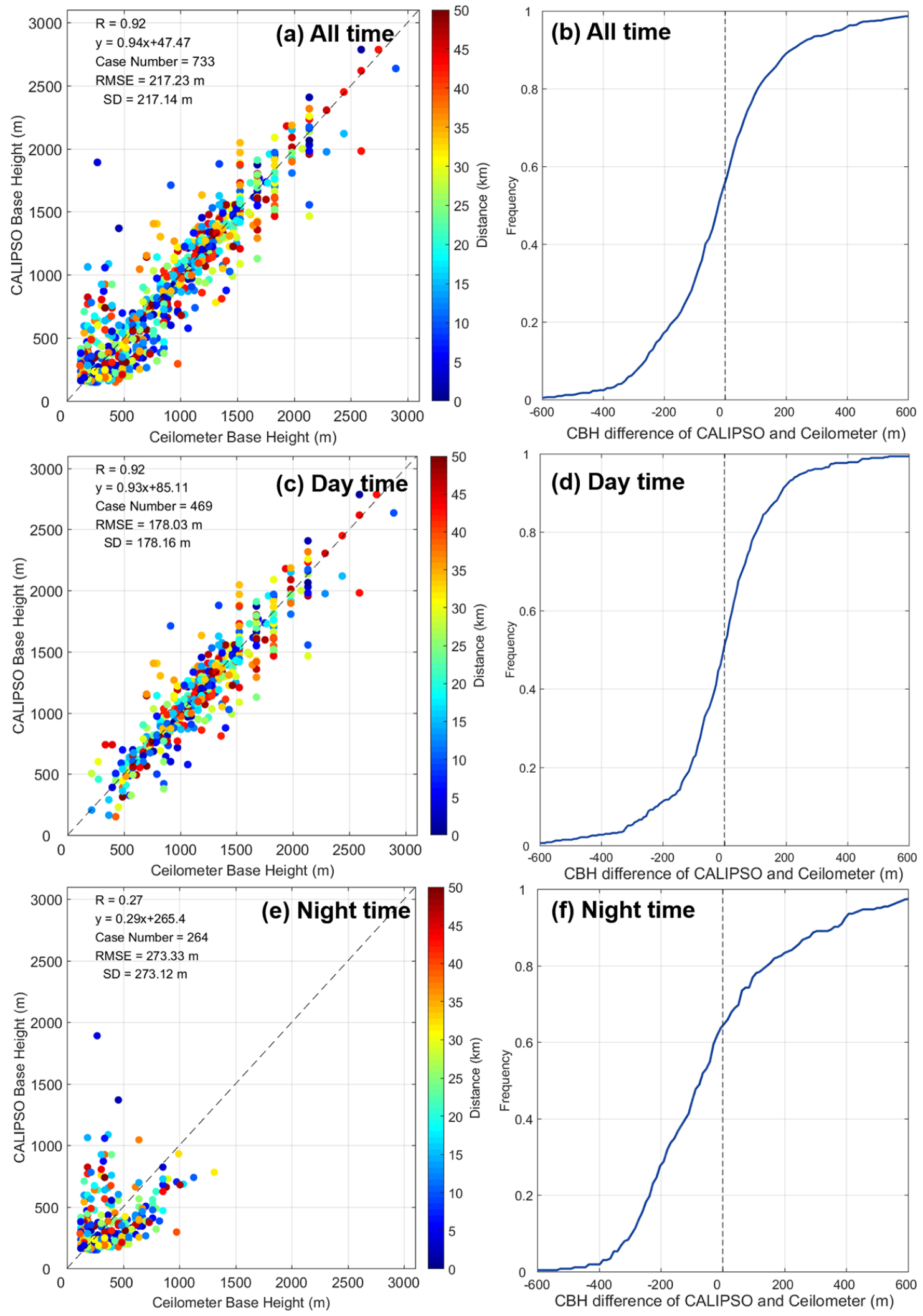

Figure 8. Validation of CALIPSO-retrieved CBH against 138 continental ceilometer sites in the southern Great Plains in 2017-2020. (a) Scatter plot of CALIPSO $\mathrm{CBH}$ and ceilometer $\mathrm{CBH}$ for all time. The color represents the shortest distance from the CALIPSO ground track to the ceilometer site. (b) Cumulative distribution of the difference between CALIPSO CBH and ceilometer CBH for all time. Panels (c) and (e) and panels (d) and (f) are the same as panels (a) and (b) but for daytime and nighttime, respectively. 

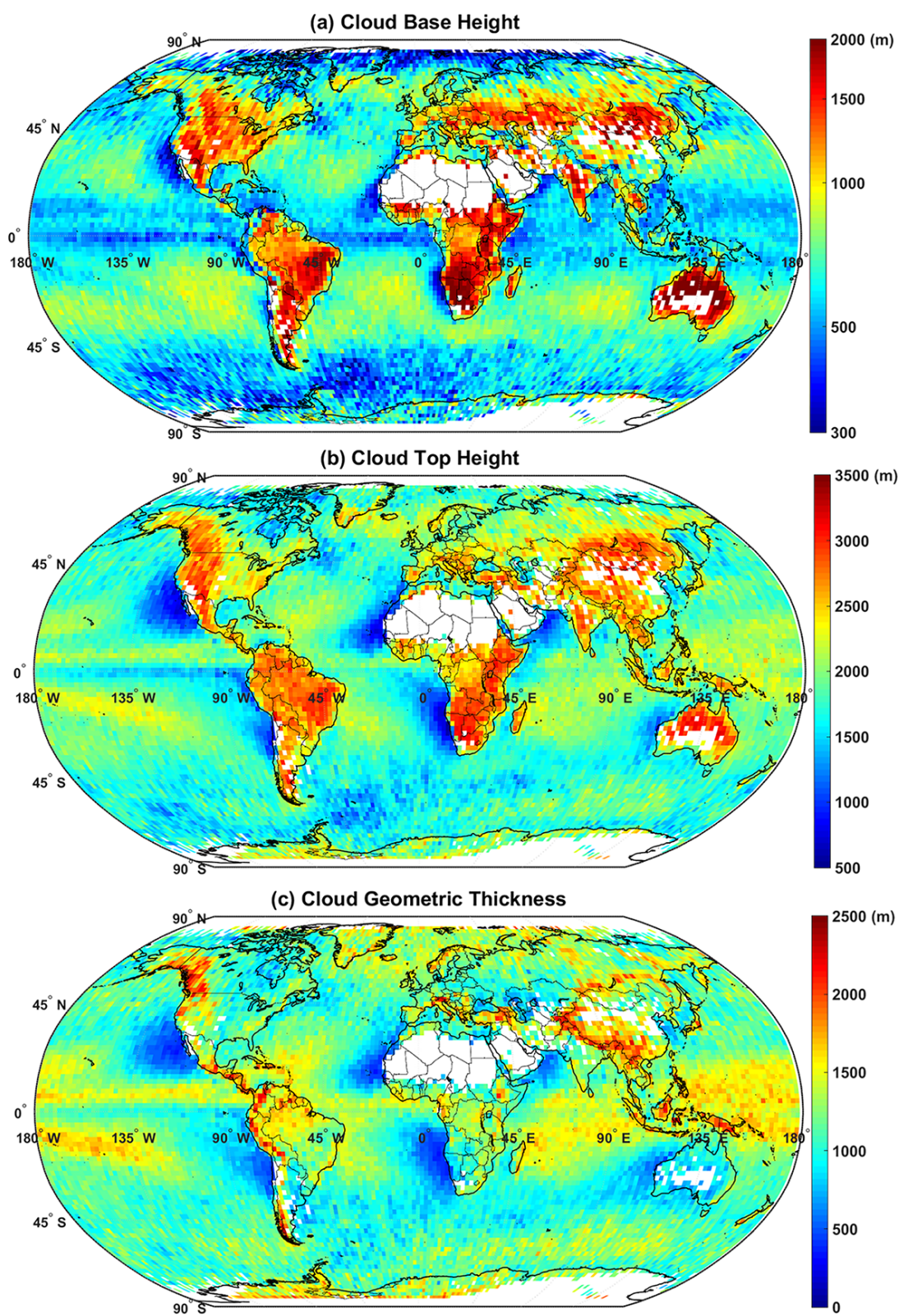

Figure 9. Geographic distributions of 2-year mean CBH, CTH, and CGT on a $2^{\circ} \times 2^{\circ}$ latitude-longitude grid in 2014 and 2017 . The heights are in meters above ground level.

with small CGTs $(<800 \mathrm{~m})$, with a percentage of $\sim 10 \%$ of all low-level clouds, occur mainly over mid-latitude oceanic regions and eastern margins of the subtropical oceans. These areas mainly include the west coast areas of South America, Africa, the United States, and Australia and are equally high-incidence areas of stratocumulus clouds (Wood, 2012). These shallow cloud geometric data retrieved in this study will be helpful to future studies of marine stratocumulus microphysics and aerosol-cloud interaction. Thick clouds with large CGTs are mainly located in the tropics and the mountainous regions, such as the western Pacific and the Rocky Mountains of western Canada.
In addition, we obtained the geographic distribution of $\mathrm{CTH}$ by taking the maximum value of $H_{\max }$ as the CTH of each $1^{\circ}$ CALIPSO scene (as shown in Fig. A5). The spatial distribution of CTH in Fig. A5a is similar to the distribution of CTH by using the mean height of the highest $10 \%$ quantile of $H_{\max }$ as the CTH (Fig. 9b). However, the cumulative distribution of the difference (Fig. A5b) indicates that the CTH based on the maximum value of $H_{\max }$ is larger than that based on the mean height of the highest $10 \%$ quantile of $H_{\max }: \sim 60 \%$ of cases have difference less than $100 \mathrm{~m}$. The maximum difference reached $300 \mathrm{~m}$, with $\sim 3 \%$ greater than $200 \mathrm{~m}$. Those areas with high differences are concentrated 
in the oceans at low latitudes, which are mainly convective clouds.

We also counted the ratio of scenes that were rejected based on each criterion (as shown in Fig. A6 in the Appendix). The results show a global average rejection ratio of $\sim 29.5 \%$, which is mainly influenced by penetration efficiency (penetration efficiency of $333 \mathrm{~m}$ resolution cloud: $28.4 \%$; penetration efficiency of all resolution cloud: $29.5 \%$ ), with less influence from multilayer clouds. In addition, the results in Fig. A6a show a higher rejection ratio at high latitudes than at middle and low latitudes, particularly in the Southern Ocean region.

\subsection{Seasonal distributions}

The seasonally averaged geographic distributions of $\mathrm{CBH}$, CTH, and CGT (Figs. 10, 11, and 12) are generally consistent with the distributions of the annual averaged results (Fig. 9) but are influenced by the variation of convective intensity in different seasons and also exhibit some unique seasonal characteristics. The $\mathrm{CBH}$ and $\mathrm{CTH}$ over land in the mid-latitude Northern Hemisphere are much greater in June-July-August (JJA) than other seasons and lowest in December-JanuaryFebruary (DJF). The mid-latitude global oceans have the lowest CBH (mostly below $500 \mathrm{~m}$ ), CTH, and CGT in summer seasons and the highest cloud top height in winter, while the $\mathrm{CBH}, \mathrm{CTH}$, and CGT distribution reversed over the highlatitude Southern Ocean. Previous study has also shown the same seasonal pattern of $\mathrm{CBH}$ and $\mathrm{CTH}$ distributions (Böhm et al., 2019) but with minimum discernible $\mathrm{CBH}>\sim 700 \mathrm{~m}$.

To further investigate the spatial variation of the cloud geometry information over land and ocean with different seasons, we plotted the mean meridional distribution maps (Fig. 13). Regional variations in $\mathrm{CBH}$ and $\mathrm{CTH}$ are more pronounced over land than over the ocean during all seasons. The CTH follows CBH, especially over land. The seasonal variations are smaller over the ocean, and $\mathrm{CBH}$ and $\mathrm{CTH}$ show the maximum variations at the winter subtropical latitudes and the summer mid-latitudes, respectively. An equatorial minimum occurs in all seasons.

\subsection{Diurnal distributions}

For the comparison of daytime and nighttime distributions, we further obtained the diurnal geographical and mean meridional distributions of $\mathrm{CBH}$ and $\mathrm{CTH}$ in Fig. 14. Over land at mid- and low latitudes, more boundary layer clouds are detected at daytime than at nighttime, as evident by the sparse coverage on the geographic distribution maps. This means that either (i) there are fewer clouds during the night or (ii) the clouds become multilayer or obscured by deep or high clouds. The opposite is true for the Southern Ocean region. Overall, the CTHs over land are much higher during the daytime than at nighttime, while over the ocean they are opposite; nighttime has slightly higher $\mathrm{CTH}$ than daytime by $\sim 300 \mathrm{~m}$ as shown by the meridional mean distributions. The $\mathrm{CBH}$ over land is greater during daytime than at nighttime, but over the ocean, the $\mathrm{CBH}$ is consistent both daytime and nighttime. The difference in CTH and CBH between land and ocean is greater during daytime than at nighttime, especially the CTH.

\section{Discussion}

The CBH retrieval accuracy in this study has been greatly improved compared to other current satellite $\mathrm{CBH}$ retrieval algorithms. This allowed gaining new insights. According to the geographic distribution maps (Fig. 9) generated from the high-accuracy $\mathrm{CBH}, \mathrm{CTH}$, and CGT data in this study, we find the following features that can be further discussed.

i. The effect of SST on $C B H$ and CGT. The patterns show the obviously higher $\mathrm{CBH}$ over land compared to the ocean, especially over the arid areas. Shallow and thin clouds prevail over cool sea surface temperatures (SSTs) to the west of subtropical coastlines and thicken gradually westward. The $\mathrm{CBH}$ increases faster than CGT with the distance from land in these regions. The thickest clouds occur over the regions with the highest SST, such as the tropical west Pacific. A conspicuous narrow strip of clouds with low CBH and CGT is noted over the Equator, most notably over the eastern half of the Pacific Ocean. This feature is the manifestation of the equatorial ocean upwelling and cooling in response to the poleward flow of surface water in response to the easterly stress by the winds (Adam, 2021).

ii. High base and thick clouds over tropical basins. CBH is lowest near the shores of South America, Namibia, and Africa because of the flow of warm continental air over the cold sea surface, which creates a strong inversion above it. This, in fact, leads to the formation of low cloud decks near the sea surface. This effect is weakening with distance from the shore. Therefore, these coastal regions are dominated by stratocumulus clouds, with CBH mainly below $\sim 400 \mathrm{~m}$ and increasing up to $\sim 1000 \mathrm{~m}$ far from the continent (the detailed distribution of $\mathrm{CBH}$ of the southeast Atlantic is shown in Fig. 15a), which is consistent with Andersen et al. (2019). The retrieved lower CBHs compared to the previous study (Mülmenstädt et al., 2018) make it possible to estimate the coupling state and its relevance to the effects of aerosols on cloud fraction based on this dataset. Over the tropical basins, such as the Amazon Basin and the Congo Basin, clouds developed high and thick with CBH larger than $1000 \mathrm{~m}$ and CGT larger than $1500 \mathrm{~m}$ (the detailed distribution of $\mathrm{CBH}$ of the Congo Basin is shown in Fig. 15b), which responds to the strong convective motion in the tropics (Sun-Mack et al., 2014). 

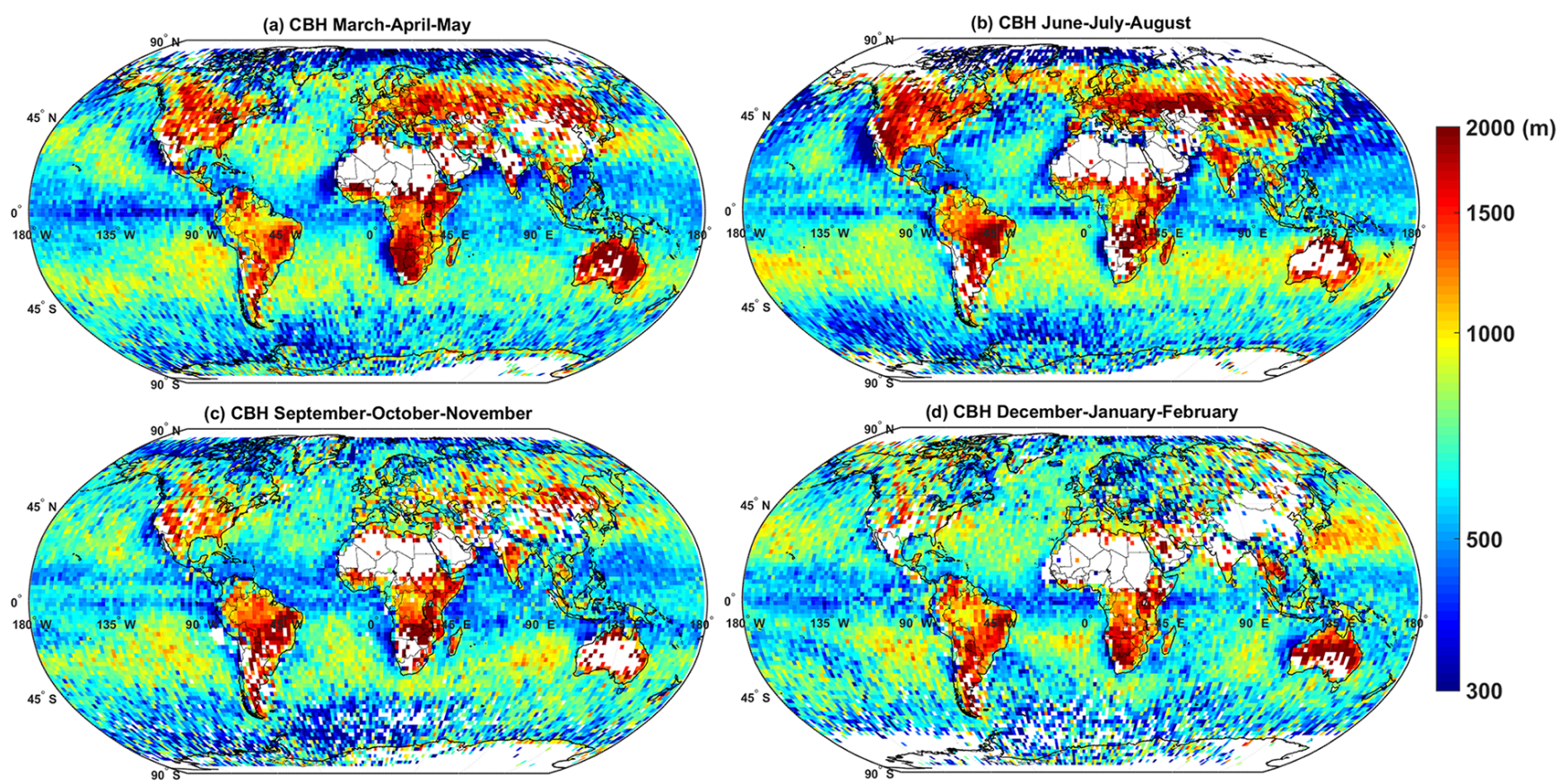

Figure 10. Geographic distributions of seasonal averaged CBH on a $2^{\circ} \times 2^{\circ}$ latitude-longitude grid in 2014 and 2017. (a) March, April, and May; (b) June, July, and August; (c) September, October, and November; (d) December, January, and February. The heights are in meters above ground level. Each grid has at least five valid scenes.
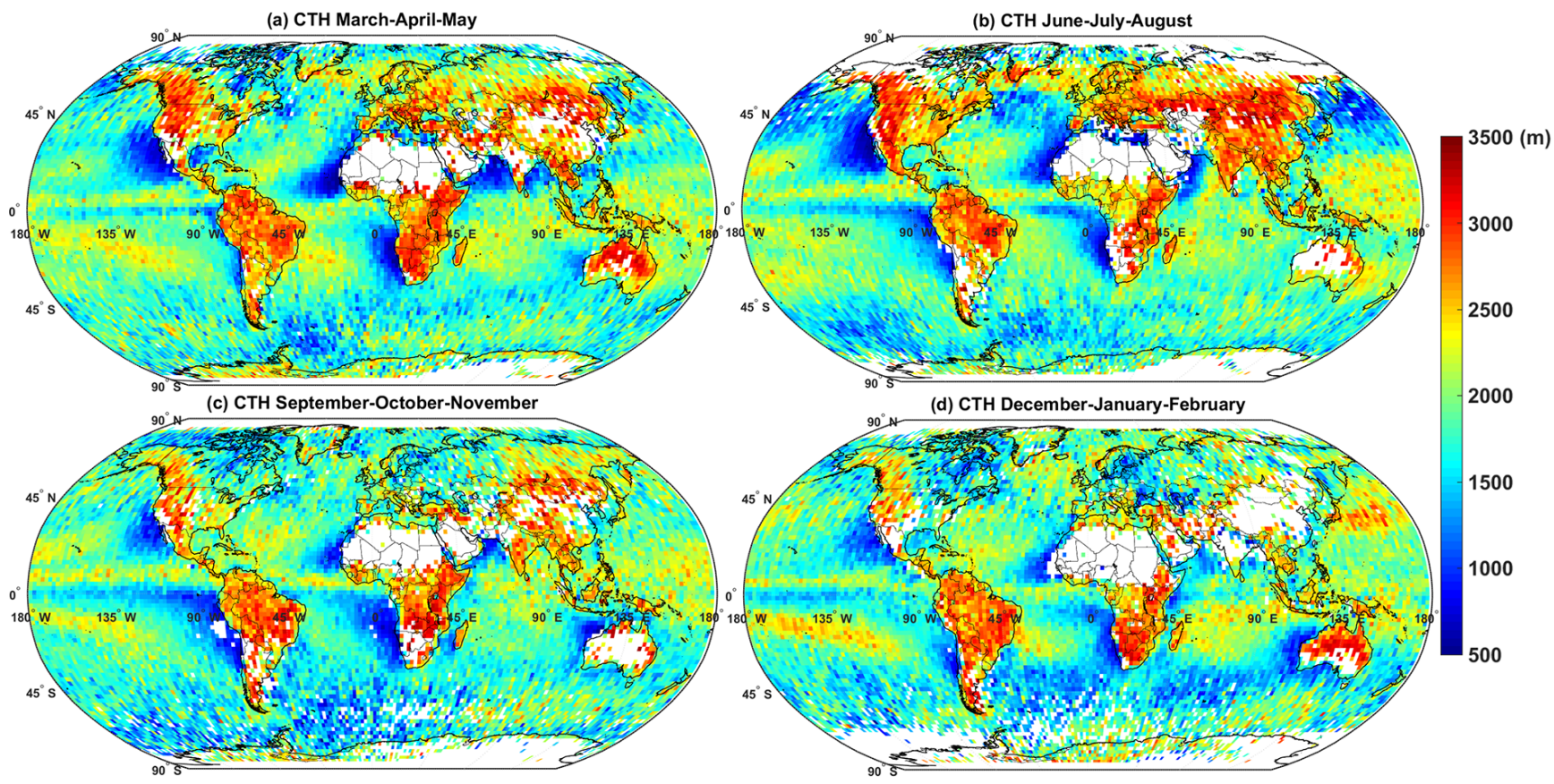

Figure 11. The same as Fig. 10 but for CTH.

iii. Large CGT and small CBH over the Southern Ocean. $\mathrm{CBH}$ is quite low over the low SST of the Southern Ocean, but CGT is much larger there than over the eastern margins of the subtropical oceans. The lowering of CBH towards Antarctica in the Southern Ocean is caused by the more frequent and stronger thermal inversions at high latitudes ( $\mathrm{Li}$ et al., 2013), with $\mathrm{CBH}$ largely below $500 \mathrm{~m}$. This is much lower than the $\sim 800 \mathrm{~m} \mathrm{CBH}$ in the Southern Ocean inferred in previous studies (Böhm et al., 2019). 

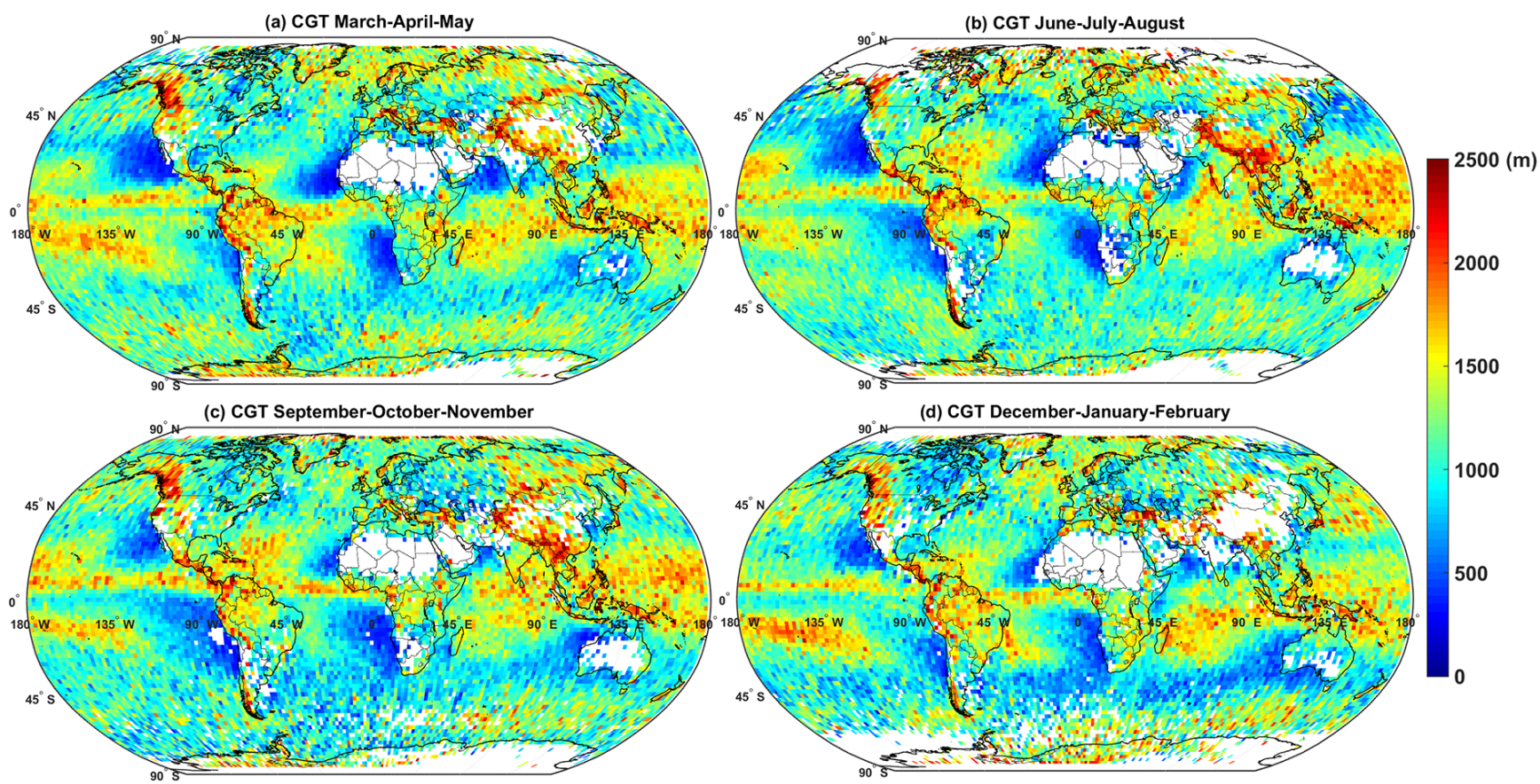

Figure 12. The same as Fig. 10 but for CGT.
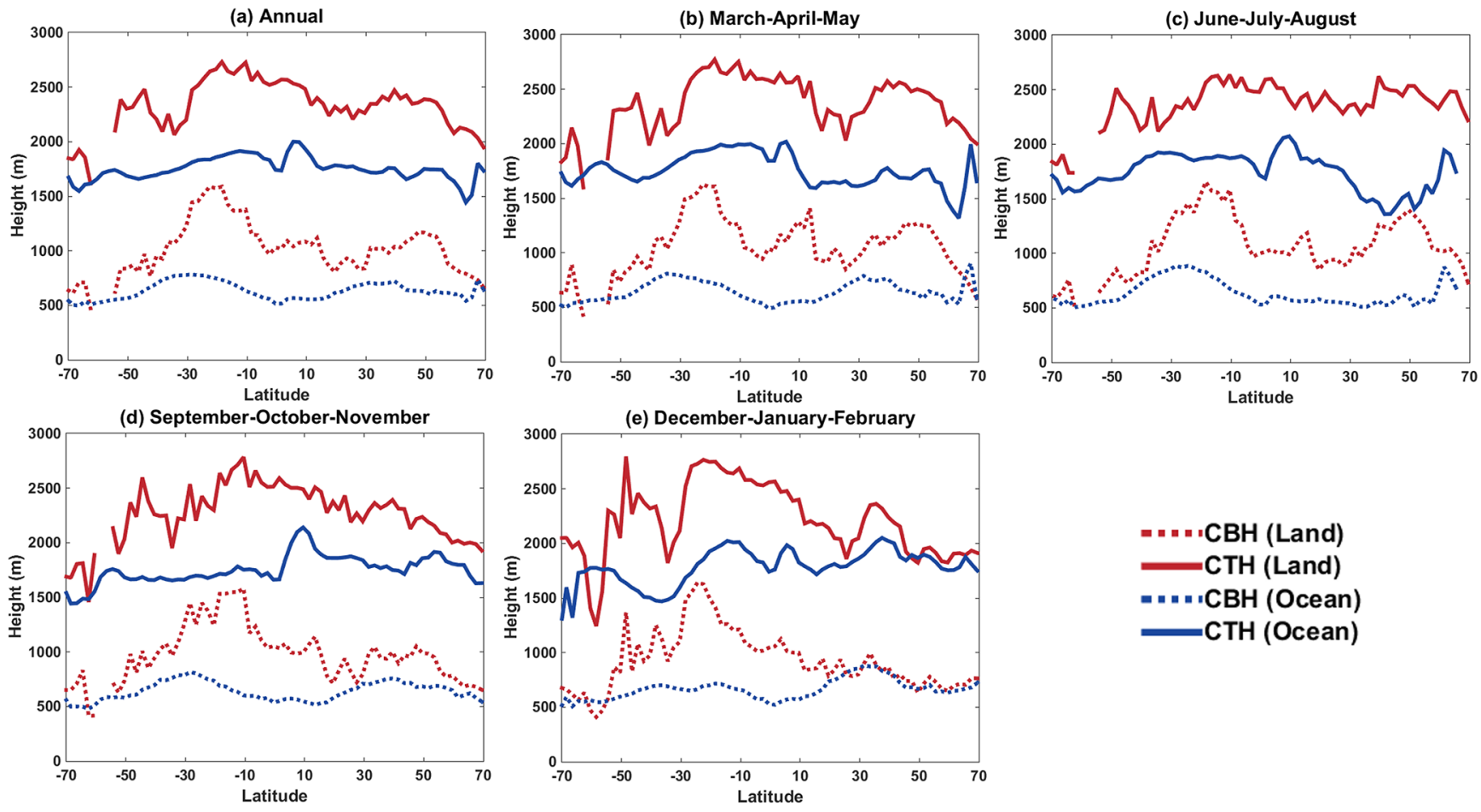

Figure 13. Mean meridian $\mathrm{CBH}$ and $\mathrm{CTH}$ annual and seasonal distributions. Straight lines indicate $\mathrm{CTH}$, and dotted lines indicate $\mathrm{CBH}$ (ocean in blue, land in red). (a) Annual; (b) March, April, and May; (c) June, July, and August; (d) September, October, and November; and (e) December, January, and February. 

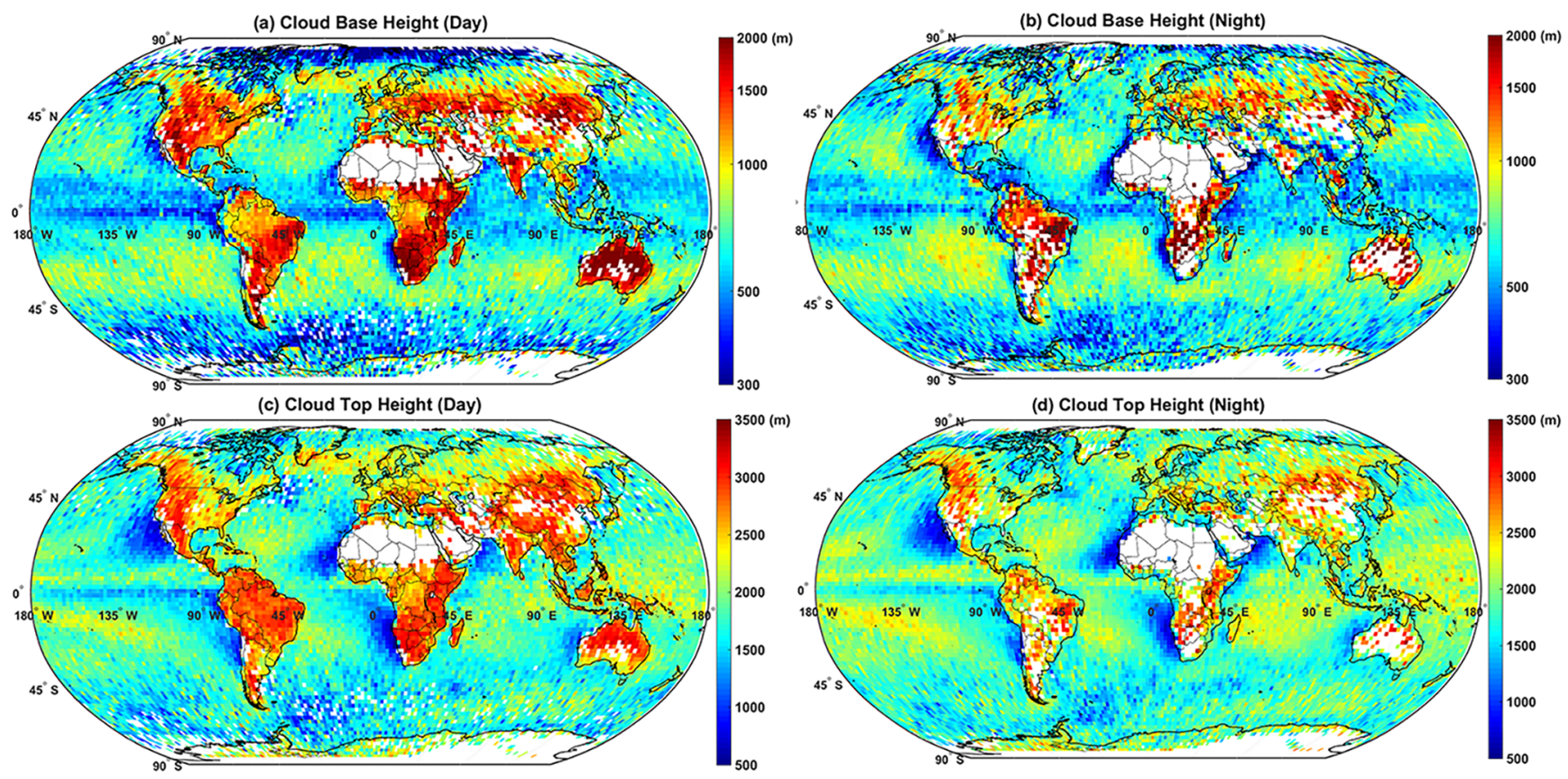

(e) Mean meridian CBH and CTH (Day)

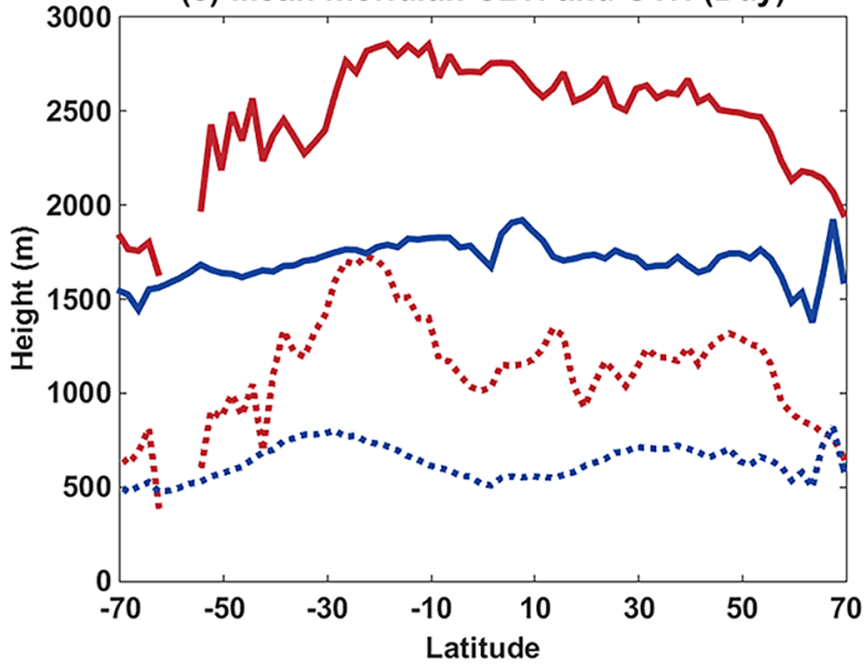

(f) Mean meridian $\mathrm{CBH}$ and $\mathrm{CTH}$ (Night)

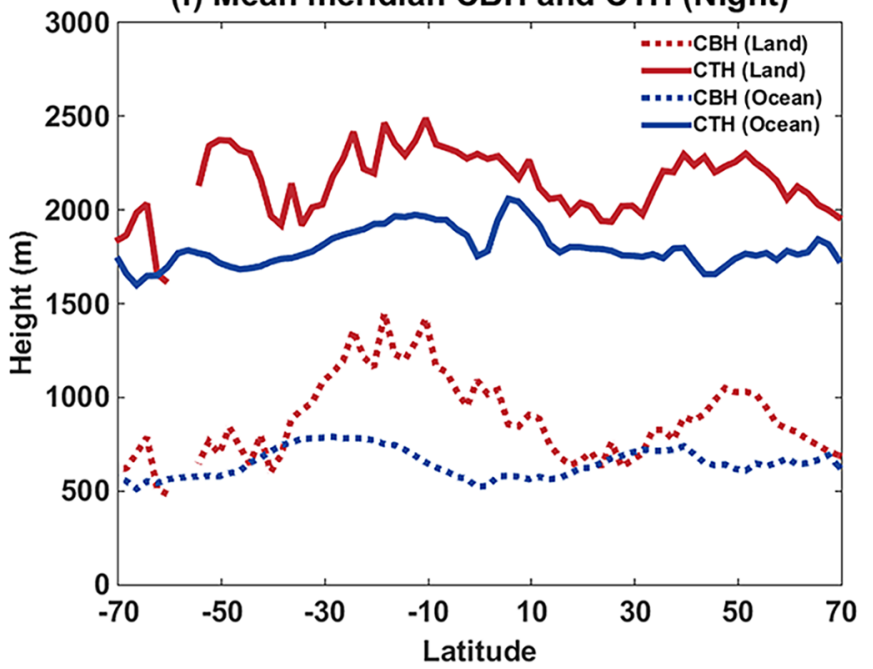

Figure 14. Geographic distributions of annual mean $\mathrm{CBH}$ on a $2^{\circ} \times 2^{\circ}$ latitude-longitude grid in 2014 and 2017 for (a) CALIPSO daytime; panel (b) is the same as panel (a) but for nighttime; panel (c) is the same as panel (a) but for CTH; panel (d) is the same as panel (c) but for nighttime. The heights are in meters above ground level. Each grid has at least 10 valid scenes. (e) Mean meridian CBH and CTH over land and the ocean for CALIPSO daytime. Straight lines indicate CTH, and dotted lines indicate CBH (ocean in blue, land in red). Panel (f) is the same as panel (e) but for nighttime.

iv. Low and thick clouds over the Maritime Continent. CBH increases rapidly over the inland region of tropical Africa, America, and Australia while keeping CGT little changed. The $\mathrm{CBH}$ increases much less over the Maritime Continent. Convection develops vigorously over those land areas, resulting in large CGT mainly greater than $1700 \mathrm{~m}$, whereas the surrounding ocean area CGT $<1700 \mathrm{~m}$ (the detailed distribution of CGT of the Maritime Continent is shown in Fig. 15c).

\section{Conclusions}

Based on the highest-resolution VFM data of CALIPSO lidar observations, a new methodology for retrieving the $\mathrm{CBH}, \mathrm{CTH}$, and CGT of low-level clouds is proposed. This methodology uses the $333 \mathrm{~m}$ resolution water cloud distribution of VFM data to retrieve CBH with superior performance. The methodology can effectively reduce the interference to CBH retrieval due to surface signal, multilayer cloud, and boundary layer aerosols. Moreover, even when the thick- 


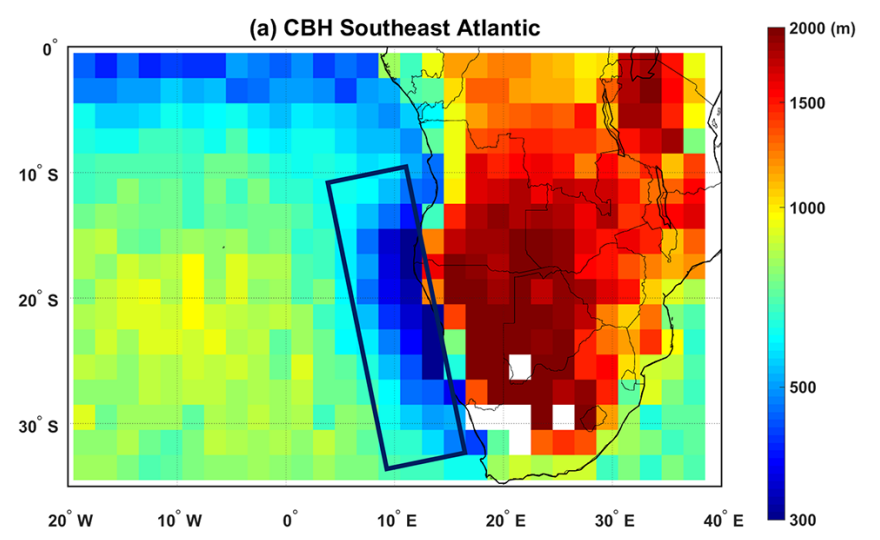

(b) $\mathrm{CBH}$ Congo Basin

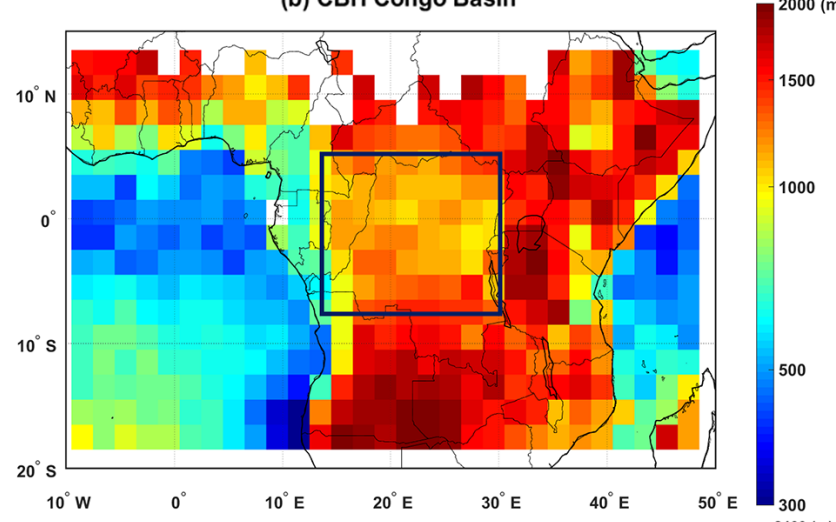

(c) CGT Maritime Continent

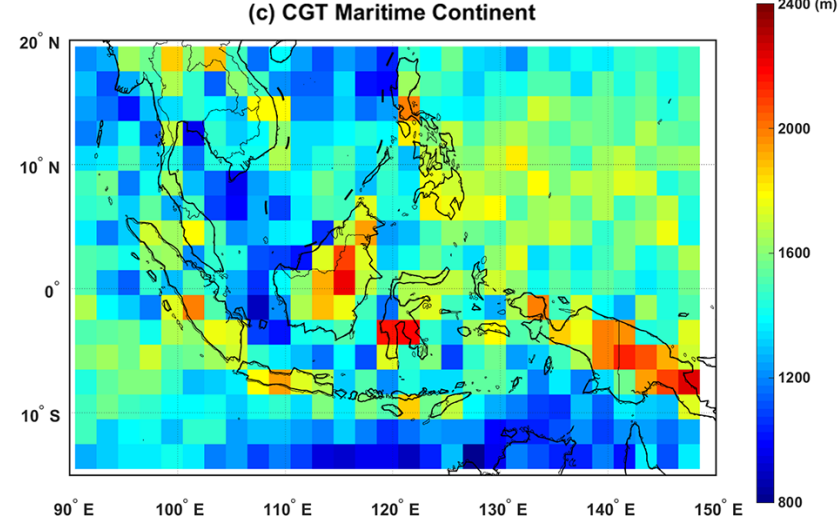

Figure 15. Geographic distributions on a $2^{\circ} \times 2^{\circ}$ latitude-longitude grid in 2014 and 2017. (a) $\mathrm{CBH}$ over the Southeast Atlantic; (b) $\mathrm{CBH}$ over the Congo Basin; (c) CGT over the Maritime Continent. The heights are in meters above ground level. The dark blue boxes represent the location of the regions of interest.

ness of the cloud is sufficient to fully attenuate the CALIPSO lidar signal, the method provides an accurate $\mathrm{CBH}$ by taking the $\mathrm{CBH}$ of the surrounding thinner cloud as representative of the entire cloud field. At the same time, we used $1^{\circ}$ scene along the CALIPSO track for CBH retrieval. In addition, the $10 \%$ quantile of all cloud base information and the $40 \%$ quantile of the first local peak were used as initial CBHs for over the ocean and land, respectively. All of these operations can reduce the effect of cloud anvils on the
CALIPSO retrieval of CBH to some extent. The methodology was developed based on observations for the year 2017 from two ocean ceilometer stations. The Pearson correlation coefficient is 0.87 , and an error standard deviation is $\pm 115 \mathrm{~m}$. Validation based on 4-year data of 138 terrestrial ceilometer sites shows that the algorithm is applicable on land with $R$ of 0.92 and an error standard deviation of $\pm 220 \mathrm{~m}$. The land algorithm differs by when taking the $40 \%$ quantile of the first local peak of CALIPSO CBH instead of the $10 \%$ quantile of all cloud base heights over the ocean. This high-precision CBH retrieval methodology developed in this study is a great improvement over other current satellite $\mathrm{CBH}$ retrieval methods with RMSE of several hundred meters or even several kilometers.

Based on this methodology, we obtained the annual, seasonal, and diurnal distributions of global $\mathrm{CBH}, \mathrm{CTH}$, and CGT for 2 years. The lowest cloud base/top heights are both concentrated in the eastern margins of the oceans in the subtropical latitudes. A narrow band of lower clouds occurs along the Equator. Seasonal analysis showed that differences in $\mathrm{CBH}$ and $\mathrm{CTH}$ were more pronounced over land than over the ocean. The seasonal variation of $\mathrm{CBH}$ and $\mathrm{CTH}$ is greater in the Northern Hemisphere than in the Southern Hemisphere, both over land and over the ocean. The diurnal distribution suggests that $\mathrm{CTH}$ is much higher over land during the daytime than at nighttime, while this phenomenon is mirrored and much weaker over the ocean. This high-precision cloud geometry information also shows several interesting features: (1) there are noticeable differences in cloud geometry characteristics between the eastern and western parts of the Pacific Ocean; (2) high base and thick clouds occur over tropical basins; (3) CBH decreases towards Antarctica in the Southern Ocean, while CGT deepens; (4) low and thick clouds occur over the Maritime Continent.

Accurate $\mathrm{CBH}$ information is of great significance for evaluating the cloud coupling state and its relevance to the effects of aerosols on cloud cover (Goren et al., 2018). The result in this study can also be applied to understanding the cloud microphysical processes and improve the accuracy of cloud radiation feedback in the numerical model (Hartmann, 2009; Yuan et al., 2006; Merk et al., 2016; ViúdezMora et al., 2015). However, we can only retrieve CGT by leaving out the high multilayer cloud fraction and low penetration efficiency of CALIPSO VFM data. Therefore, the current method cannot deal with CALIPSO scenes with a large amount of multilayer clouds and non-penetration optical thick clouds. 


\section{Appendix A}

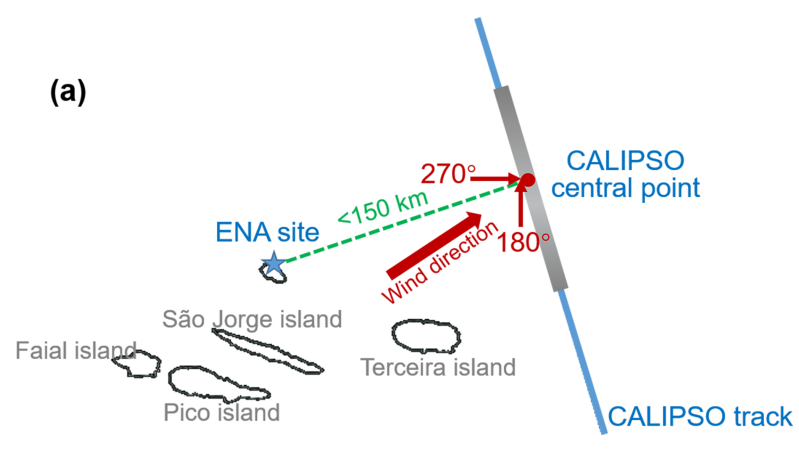

(b)

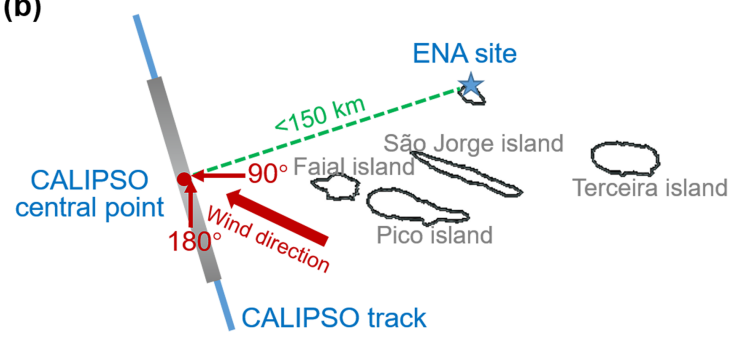

Figure A1. Schematic of matching between the CALIPSO and the ENA observation site. The blue star indicates the location of the ceilometer site, the blue line is the CALIPSO track, the red circle represents the CALIPSO central point, the dashed green line represents the shortest distance from the site to the CALIPSO central point, the gray shaded area is the $1^{\circ}$ CALIPSO scene, and the red arrow represents the wind direction of the CALIPSO data. (a) The CALIPSO track is located at the eastern ocean of ENA site. Wind directions of rejected CALIPSO data: $180-270^{\circ}$. (b) The CALIPSO track is located at the western ocean of ENA site. Wind directions of rejected CALIPSO data: $90-180^{\circ}$.

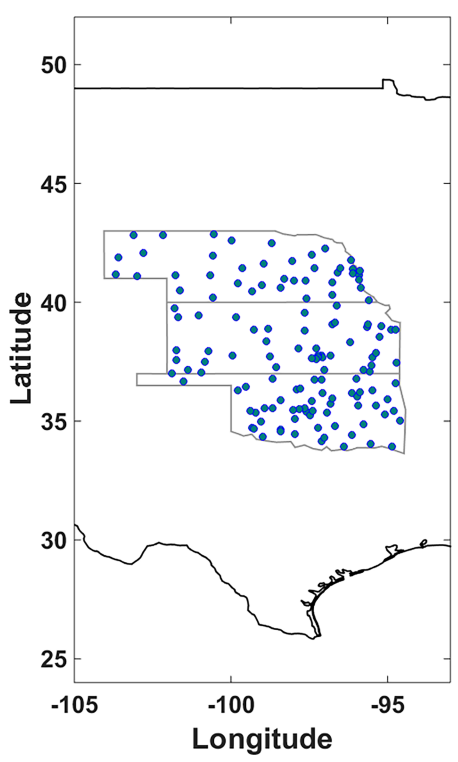

Figure A2. The ASOS ceilometer distribution over land used for $\mathrm{CBH}$ evaluation. 

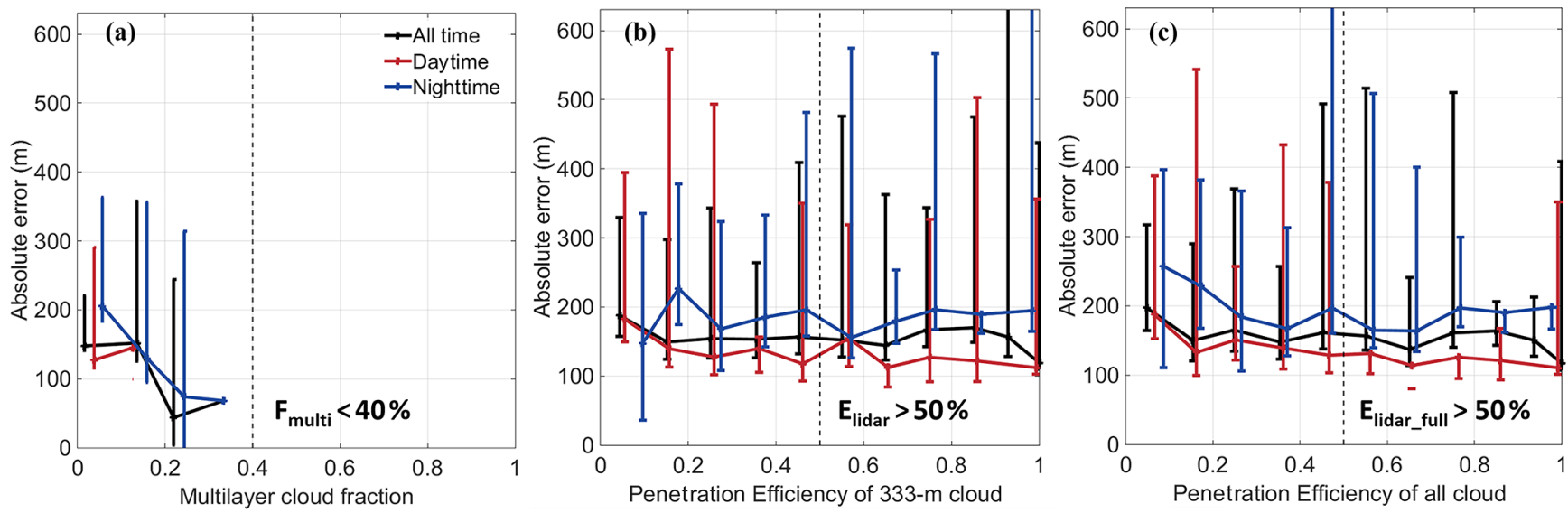

Figure A3. (a) Joint distribution of CBH absolute error (between CALIPSO CBH and ceilometer CBH) and multilayer cloud fraction of 138 continental ceilometer sites in the southern Great Plains in 2017-2020 with distance less than $50 \mathrm{~km}$. The different colored lines represent different times (the black line: all time; the red line: daytime; the blue line: nighttime). The standard error is shown by error bars. Panel (b) is the same as panel (a) but for penetration efficiency of $333 \mathrm{~m}$ resolution cloud. Panel (c) is the same as panel (a) but for penetration efficiency of all clouds.
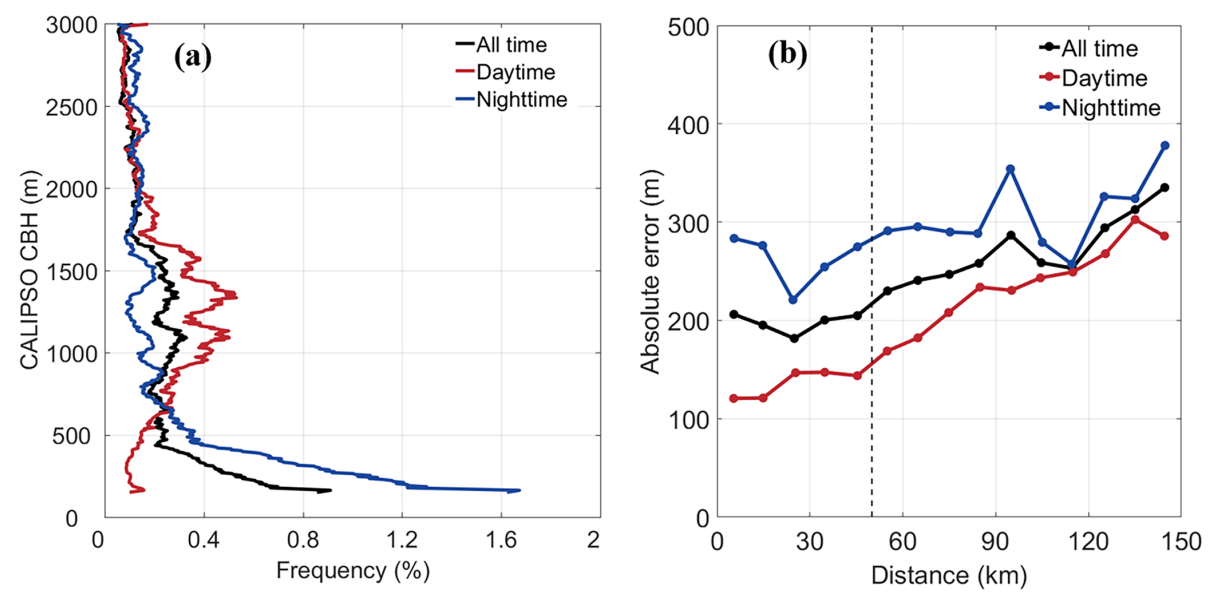

Figure A4. (a) Frequency profile of CALIPSO-retrieved CBH of 138 continental ceilometer sites in the southern Great Plains in 20172020. The different colored lines represent different times (the black line: all time; the red line: daytime; the blue line: nighttime). (b) Joint distribution of $\mathrm{CBH}$ absolute error (between CALIPSO $\mathrm{CBH}$ and ceilometer $\mathrm{CBH}$ ) and distance (that is the shortest distance from the CALIPSO ground track to the ceilometer site) of 138 continental ceilometer sites in the southern Great Plains in 2017-2020. The different colored lines represent different times (the black line: all time; the red line: daytime; the blue line: nighttime). 
(a) Cloud Top Height

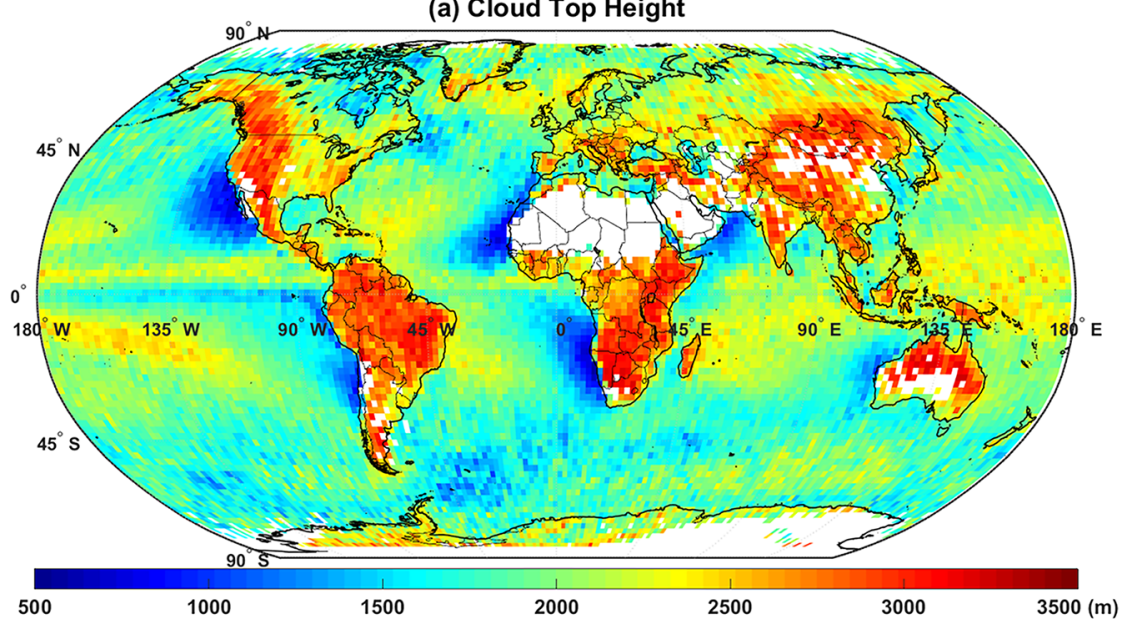

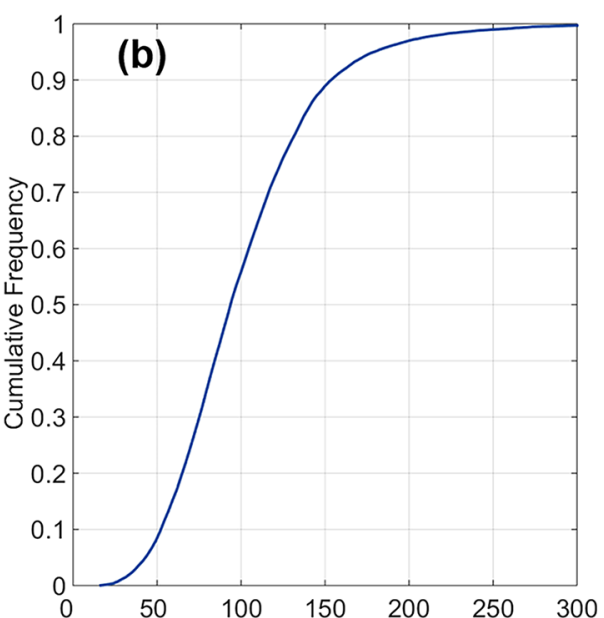

Figure A5. (a) Geographic distribution of CTH based on the maximum value of $H_{\max }$ on a $2^{\circ} \times 2^{\circ}$ latitude-longitude grid in 2014 and 2017. (b) Cumulative distribution of the difference between the $\mathrm{CTH}$ based on the maximum value of $H_{\max }$ and $\mathrm{CTH}$ based on the mean height of the highest $10 \%$ quantile of $H_{\max }$ in 2014 and 2017. The heights are in meters above ground level.
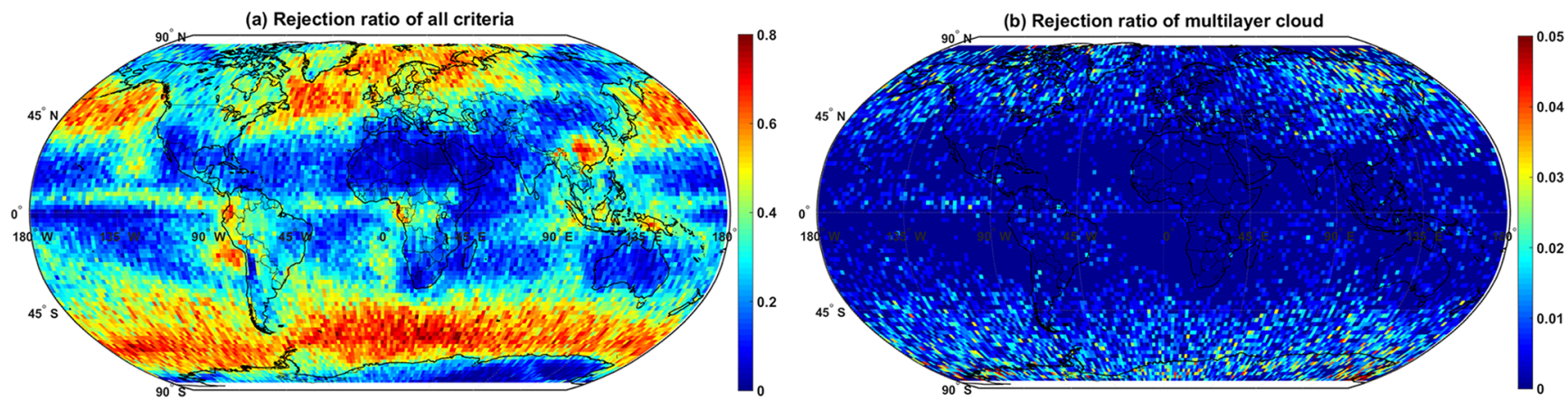

(c) Rejection ratio of penetration efficiency of 333-m cloud

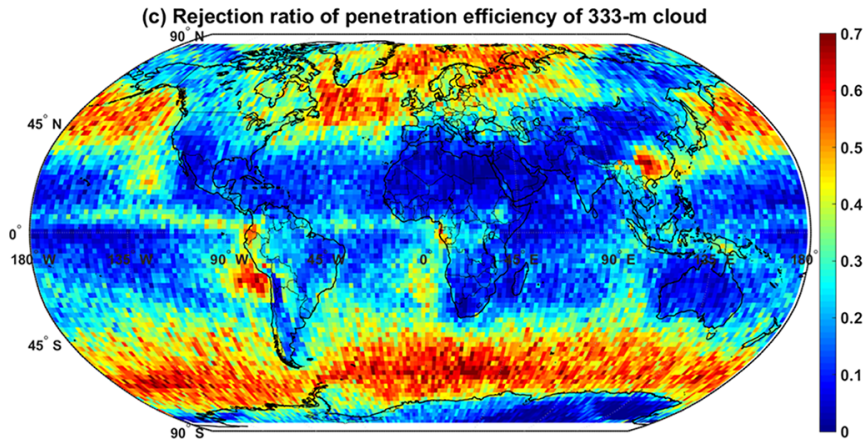

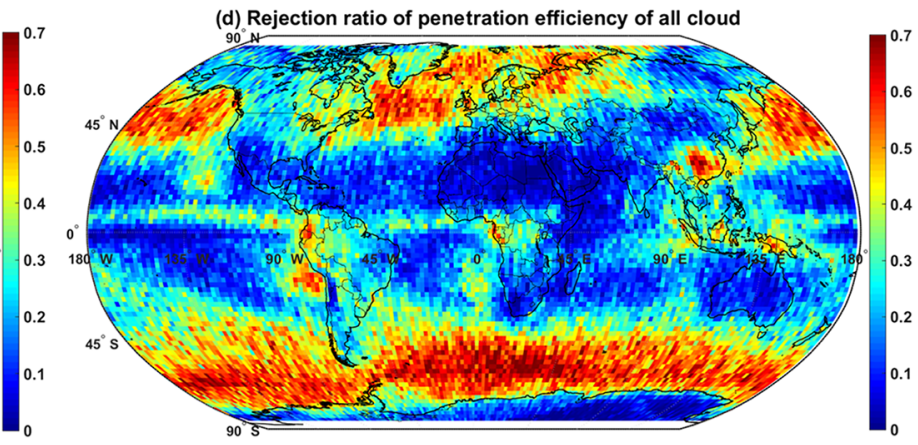

Figure A6. (a) Geographic distribution of rejection ratio of all criteria (multilayer cloud, penetration efficiency of $333 \mathrm{~m}$ resolution cloud, and penetration efficiency of all resolution cloud) on a $2^{\circ} \times 2^{\circ}$ latitude-longitude grid in 2014 and 2017. Panels (b), (c), and (d) are the same as panel (a) but for multilayer cloud, penetration efficiency of $333 \mathrm{~m}$ resolution cloud, and penetration efficiency of all resolution cloud, respectively. 


\section{Appendix B}

Table B1. Validation statistics of CALIPSO-retrieved initial CBH for different conditions of 138 continental ceilometer sites in the southern Great Plains in 2017-2020. The values in bold are the retrieval criteria that we used over the land.

\begin{tabular}{lrr}
\hline & Case number & RMSE (m) \\
\hline min CALIPSO CBH & 8404 & 635 \\
$H_{\text {min }}$ at $10 \%$ quantile (same as ocean) & 7963 & 665 \\
$10 \%$ quantile of the first local peak & 8302 & 616 \\
$20 \%$ quantile of the first local peak & 8280 & 615 \\
$30 \%$ quantile of the first local peak & 8270 & 619 \\
$\mathbf{4 0} \%$ quantile of the first local peak & $\mathbf{8 2 0 3}$ & $\mathbf{6 1 2}$ \\
$50 \%$ quantile of the first local peak & 8225 & 618 \\
$60 \%$ quantile of the first local peak & 8193 & 619 \\
$70 \%$ quantile of the first local peak & 8169 & 628 \\
\hline
\end{tabular}

Table B2. Final retrieval criteria used over the ocean and land.

\begin{tabular}{lll}
\hline Criteria & Over the ocean & Over land \\
\hline Retrieval domain & $<100 \mathrm{~km}$ & $<50 \mathrm{~km}$ \\
Initial CALIPSO CBH & $10 \%$ quantile of all cloud base & $40 \%$ quantile of the first local peak \\
$F_{\text {multi }}$ & $<40 \%$ & $<40 \%$ \\
$E_{\text {lidar }}$ & $>50 \%$ & $>50 \%$ \\
$E_{\text {lidar_full }}$ & $>50 \%$ & $>50 \%$ \\
\hline
\end{tabular}


Data availability. The CALIPSO VFM data used in this study are available at https://doi.org/10.5067/CALIOP/CALIPSO/LID_ L2_VFM-STANDARD-V4-20 (NASA/LARC/SD/ASDC, 2018), Atmospheric Radiation Measurement ceilometer observation data are obtained from https://adc.arm.gov/ discovery/\#/results/site_code::ena/meas_category_code::

cloud/meas_subcategory_detail::cloud.macro (ARM, 2021), Barbados Cloud Observatory data are available at https://www. mpimet.mpg.de/en/science/the-atmosphere-in-the-earth-system/ working-groups/tropical-cloud-observation/barbadosstation1/ instrumentation-and-data/ (BCO, 2021), and the ASOS ceilometer data source is https://mesonet.agron.iastate.edu/request/download. phtml (ASOS, 2021).

Author contributions. DR conceived the study. XL, YZ, and DR designed the cloud base height and geometric thickness retrieval methodology. XL implemented the methodology and carried out the data analysis with help from YZ and FM. ZP, FM, and WG provided useful comments on the paper. XL prepared the manuscript with contributions from YZ, DR, and the other co-authors.

Competing interests. The authors declare that they have no conflict of interest.

Disclaimer. Publisher's note: Copernicus Publications remains neutral with regard to jurisdictional claims in published maps and institutional affiliations.

Acknowledgements. We are grateful to the science teams for providing excellent and accessible CALIPSO, Atmospheric Radiation Measurement ceilometer observation, and Barbados Cloud Observatory data.

Financial support. This research has been supported by the National Natural Science Foundation of China (grant nos. 41971285, 41627804, and 42075093), the National Key Research and Development Program of China (grant no. 2018YFC1507903), and the Fundamental Research Funds for the Central Universities (grant no. 2042019kf0192).

Review statement. This paper was edited by Johannes Quaas and reviewed by two anonymous referees.

\section{References}

Adam, O.: Dynamic and energetic constraints on the modality and position of the intertropical convergence zone in an aquaplanet, J. Climate, 34, 527-543, 2021.

Albrecht, B. A.: Aerosols, cloud microphysics, and fractional cloudiness, Science, 245, 1227-1230, https://doi.org/10.1126/science.245.4923.1227, 1989.
Andersen, H., Cermak, J., Solodovnik, I., Lelli, L., and Vogt, R.: Spatiotemporal dynamics of fog and low clouds in the Namib unveiled with ground- and space-based observations, Atmos. Chem. Phys., 19, 4383-4392, https://doi.org/10.5194/acp-194383-2019, 2019.

ARM: Ceilometer (CEIL): cloud-base heights, ARM Data Center [data set], Oak Ridge, Tennessee, USA, available at: https://adc.arm.gov/discovery/\#/results/site_code::ena/meas_ category_code::cloud/meas_subcategory_detail::cloud.macro, last access: 5 August 2021.

ASOS: Automated Surface Observation System: cloud-base heights, Iowa Environmental Mesonet of Iowa State University [data set], https://mesonet.agron.iastate.edu/request/download. phtml, last access: 5 August 2021.

Baker, N.: Joint Polar Satellite System (JPSS) VIIRS cloud base height algorithm theoretical basis document (ATBD), in: Technical Report JPSS Ground Project Code 474-00045, NASA Goddard, Space Flight Center: Greenbelt, MD, USA, 2011.

BCO: The Barbados Cloud Observatory, Repository for Archiving and MAnaging Diverse DAta (RAMADDA) [data set], available at: https://www.mpimet. mpg.de/en/science/the-atmosphere-in-the-earth-system/ working-groups/tropical-cloud-observation/barbadosstation1/ instrumentation-and-data/, last access: 5 August 2021.

Böhm, C., Sourdeval, O., Mülmenstädt, J., Quaas, J., and Crewell, S.: Cloud base height retrieval from multi-angle satellite data, Atmos. Meas. Tech., 12, 1841-1860, https://doi.org/10.5194/amt12-1841-2019, 2019.

Burton, S. P., Ferrare, R. A., Vaughan, M. A., Omar, A. H., Rogers, R. R., Hostetler, C. A., and Hair, J. W.: Aerosol classification from airborne HSRL and comparisons with the CALIPSO vertical feature mask, Atmos. Meas. Tech., 6, 13971412, https://doi.org/10.5194/amt-6-1397-2013, 2013.

Dupont, J. C., Haeffelin, M., Morille, Y., Comstock, J. M., Flynn, C., Long, C. N., Sivaraman, C., and Newson, R. K.: Cloud properties derived from two lidars over the ARM SGP site, Geophys. Res. Lett., 38, 99-106, 2011.

Efraim, A., Rosenfeld, D., Schmale, J., and Zhu, Y.: Satellite Retrieval of Cloud Condensation Nuclei Concentrations in Marine Stratocumulus by Using Clouds as CCN Chambers, J. Geophys. Res.-Atmos., 125, e2020JD032409, https://doi.org/10.1029/2020JD032409, 2020.

Fitch, K. E., Hutchison, K. D., Bartlett, K. S., Wacker, R. S., and Gross, K. C.: Assessing VIIRS cloud base height products with data collected at the Department of Energy Atmospheric Radiation Measurement sites, Int. J. Remote Sens., 37, 2604-2620. 2016.

Garrett, T. J. and Zhao, C.: Increased Arctic cloud longwave emissivity associated with pollution from mid-latitudes, Nature, 440, 787-789, https://doi.org/10.1038/nature04636, 2006.

Goren, T., Rosenfeld, D., Sourdeval, O., and Quaas, J.: Satellite Observations of Precipitating Marine Stratocumulus Show Greater Cloud Fraction for Decoupled Clouds in Comparison to Coupled Clouds, Geophys. Res. Lett., 45, 5126-5134, 2018.

Grosvenor, D. P. and Wood, R.: The effect of solar zenith angle on MODIS cloud optical and microphysical retrievals within marine liquid water clouds, Atmos. Chem. Phys., 14, 7291-7321, https://doi.org/10.5194/acp-14-7291-2014, 2014. 
Grosvenor, D. P., Field, P. R., Hill, A. A., and Shipway, B. J.: The relative importance of macrophysical and cloud albedo changes for aerosol-induced radiative effects in closed-cell stratocumulus: insight from the modelling of a case study, Atmos. Chem. Phys., 17, 5155-5183, https://doi.org/10.5194/acp17-5155-2017, 2017.

Hahn, C. J., Rossow, W. B., and Warren, S. G.: ISCCP Cloud Properties Associated with Standard Cloud Types Identified in Individual Surface Observations, J. Climate, 14, 11-28, 2001.

Ham, S.-H., Kato, S., Rose, F. G., Winker, D., L'Ecuyer, T., Mace, G. G., Painemal, D., Sun-Mack, S., Chen, Y., and Miller, W. F.: Cloud occurrences and cloud radiative effects (CREs) from CERES-CALIPSO-CloudSat-MODIS (CCCM) and CloudSat radar-lidar (RL) products, J. Geophys. Res.-Atmos., 122, 8852-8884, https://doi.org/10.1002/2017JD026725, 2017.

Hartmann, D. L.: Understanding the Importance of Microphysics and Macrophysics for Warm Rain in Marine Low Clouds. Part II: Heuristic Models of Rain Formation, J. Atmos. Sci., 66, 2973 2990, 2009.

Lenaerts, J. T., Gettelman, A., Van Tricht, K., van Kampenhout, L., and Miller, N. B.: Impact of Cloud Physics on the Greenland Ice Sheet Near-Surface Climate: A Study With the Community Atmosphere Model, J. Geophys. Res.-Atmos., 125, e2019JD031470, https://doi.org/10.1029/2019JD031470, 2020.

Li, J. M., Yi, Y. H., Stamnes, K., Ding, X. D., Wang, T. H., Jin, H. C., and Wang, S. S.: A new approach to retrieve cloud base height of marine boundary layer clouds, Geophys. Res. Lett., 40, 4448-4453, https://doi.org/10.1002/grl.50836, 2013.

Ma, Z., Liu, Q., Zhao, C., Shen, X., Wang, Y., Jiang, J. H., Li, Z., and Yung, Y.: Application and Evaluation of an Explicit Prognostic Cloud-Cover Scheme in GRAPES Global Forecast System, J. Adv. Model. Earth Syst., 10, 652-667, https://doi.org/10.1002/2017MS001234, 2018.

Mace, G. G. and Zhang, Q.: The CloudSat radar-lidar geometrical profile product (RL-GeoProf): Updates, improvements, and selected results, J. Geophys. Res.-Atmos., 119, 9441-9462, 2014.

Merk, D., Deneke, H., Pospichal, B., and Seifert, P.: Investigation of the adiabatic assumption for estimating cloud micro- and macrophysical properties from satellite and ground observations, Atmos. Chem. Phys., 16, 933-952, https://doi.org/10.5194/acp-16933-2016, 2016.

Mülmenstädt, J., Sourdeval, O., Henderson, D. S., L'Ecuyer, T. S., Unglaub, C., Jungandreas, L., Böhm, C., Russell, L. M., and Quaas, J.: Using CALIOP to estimate cloud-field base height and its uncertainty: the Cloud Base Altitude Spatial Extrapolator (CBASE) algorithm and dataset, Earth Syst. Sci. Data, 10, 2279-2293, https://doi.org/10.5194/essd-10-2279-2018, 2018.

NASA/LARC/SD/ASDC: CALIPSO Lidar Level 2 Vertical Feature Mask (VFM), V4-20, NASA Langley Atmospheric Science Data Center DAAC [data set], https://doi.org/10.5067/CALIOP/CALIPSO/LID_L2_VFMSTANDARD-V4-20, 2018.

Noh, Y. J., Forsythe, J. M., Miller, S. D., Seaman, C. J., Li, Y., Heidinger, A. K., Lindsey, D. T., Rogers, M. A., and Partain, P. T.: Cloud-Base Height Estimation from VIIRS. Part II: A Statistical Algorithm Based on A-Train Satellite Data, J. Atmos. Ocean. Tech., 34, 585-598, 2017.

Rosenfeld, D., Zheng, Y., Hashimshoni, E., Pöhlker, M. L., and Andreae, M. O.: Satellite retrieval of cloud condensation nuclei con- centrations by using clouds as CCN chambers, P. Natl. Acad. Sci. USA, 113, 5828-5834, 2016.

Rosenfeld, D., Zhu, Y., Wang, M., Zheng, Y., Goren, T., and Yu, S.: Aerosol-driven droplet concentrations dominate coverage and water of oceanic low-level clouds, Science, 363, eaav0566, https://doi.org/10.1126/science.aav0566, 2019.

Sato, Y. and Suzuki, K.: How do aerosols affect cloudiness?, Science, 363, 580-581, 2019.

Scheirer, R. and Macke, A.: Cloud inhomogeneity and broadband solar fluxes, J. Geophys. Res.-Atmos., 108, 4599, https://doi.org/10.1029/2002JD003321, 2003.

Seaman, C. J., Noh, Y. J., Miller, S. D., Heidinger, A. K., and Lindsey, D. T.: Cloud-Base Height Estimation from VIIRS. Part I: Operational Algorithm Validation against CloudSat, J. Atmos. Ocean. Tech., 34, 567-583, 2017.

Stephens, G. L. and Webster, P. J.: Cloud Decoupling of the Surface and Planetary Radiative Budgets, J. Atmos. Sci., 41, 681-686, 2010.

Stephens, G. L., Christensen, M., Andrews, T., Haywood, J., and Sy, O.: Cloud Physics from Space, Q. J. Roy. Meteor. Soc., 145, 2854-2875, 2019.

Sun-Mack, S., Minnis, P., Yan, C., Kato, S., and Winker, D. M.: Regional apparent boundary layer lapse rates determined from CALIPSO and MODIS data for cloud height determination, J. Appl. Meteorol. Clim., 53, 990-1011, 2014.

Twomey, S.: Pollution and the planetary albedo, Atmos. Environ., 8, 1251-1256, 1974.

Twomey, S.: The Influence of Pollution on the Shortwave Albedo of Clouds, J. Atmos. Sci., 34, 1149-1152, https://doi.org/10.1175/15200469(1977)034<1149:tiopot>2.0.co;2, 1977.

Vaughan, M. A., Winker, D. M., and Powell, K. A.: CALIOP algorithm theoretical basis document, part 2: Feature detection and layer properties algorithms, PC-SCI-202.01, NASA Langley Res. Cent., Hampton, Va, USA, available at: http://www-calipso. larc.nasa.gov/resources/project_documentation.php (last access: 5 August 2021), 2005.

Viúdez-Mora, A., Costa-Surós, M., Calbó, J., and González, J. A.: Modeling atmospheric longwave radiation at the surface during overcast skies: The role of cloud base height, J. Geophys. Res.Atmos., 120, 199-214, 2015.

Wang, Y., Zhao, C., Dong, Z., Li, Z., Hu, S., Chen, T., Tao, F., and Wang, Y.: Improved retrieval of cloud base heights from ceilometer using a non-standard instrument method, Atmos. Res., 202 , 148-155, 2018.

Weisz, E., Li, J., Menzel, W. P., Heidinger, A. K., Kahn, B. H., and Liu, C. Y.: Comparison of AIRS, MODIS, CloudSat and CALIPSO cloud top height retrievals, Geophys. Res. Lett., 34, L17811, https://doi.org/10.1029/2007GL030676, 2007.

Winker, D. M., Hunt, W. H., and Mcgill, M. J.: Initial performance assessment of CALIOP, Geophys. Res. Lett., 34, L19803, https://doi.org/10.1029/2007GL030135, 2007.

Winker, D. M., Vaughan, M. A., Omar, A., Hu, Y., Powell, K. A., Liu, Z., Hunt, W. H., and Young, S. A.: Overview of the CALIPSO Mission and CALIOP Data Processing Algorithms, J. Atmos. Ocean. Tech., 26, 2310-2323, 2009.

Wood, R.: Stratocumulus clouds, Mon. Weather Rev., 140, 2373 2423, 2012. 
Yang, Y., Zhao, C., and Fan, H.: Spatiotemporal distributions of cloud properties over China based on Himawari-8 advanced Himawari imager data, Atmos. Res., 240, 104927, https://doi.org/10.1016/j.atmosres.2020.104927, 2020.

Yuan, J., Fu, Q., and McFarlane, N.: Tests and improvements of GCM cloud parameterizations using the CCCMA SCM with the SHEBA data set, Atmos. Res., 82, 222-238, 2006.

Zhao, C. F., Xie, S. C., Klein, S. A., Protat, A., Shupe, M. D., McFarlane, S. A., Comstock, J. M., Delanoe, J., Deng, M., Dunn, M., Hogan, R. J., Huang, D., Jensen, M. P., Mace, G. G., McCoy, R., O'Connor, E. J., Turner, D. D., and Wang, Z.: Toward understanding of differences in current cloud retrievals of ARM ground-based measurements, J. Geophys. Res.-Atmos., 117, D10206, https://doi.org/10.1029/2011jd016792, 2012.

Zhao, S. and Suzuki, K.: Differing Impacts of Black Carbon and Sulfate Aerosols on Global Precipitation and the ITCZ Location via Atmosphere and Ocean Energy Perturbations, J. Climate, 32, 5567-5582, https://doi.org/10.1175/jcli-d-18-0616.1, 2019.

Zheng, Y.: Theoretical Understanding of the Linear Relationship between Convective Updrafts and Cloud-Base Height for Shallow Cumulus Clouds. Part I: Maritime Conditions, J. Atmos. Sci., 76, 2539-2558, https://doi.org/10.1175/jas-d-18-0323.1, 2019.
Zheng, Y. and Rosenfeld, D.: Linear relation between convective cloud base height and updrafts and application to satellite retrievals, Geophys. Res. Lett., 42, 6485-6491, 2015.

Zheng, Y., Sakradzija, M., Lee, S.-S., and Li, Z.: Theoretical Understanding of the Linear Relationship between Convective Updrafts and Cloud-Base Height for Shallow Cumulus Clouds. Part II: Continental Conditions, J. Atmos. Sci., 77, 1313-1328, https://doi.org/10.1175/jas-d-19-0301.1, 2020.

Zhu, Y., Rosenfeld, D., Yu, X., Liu, G., Dai, J., and Xu, X.: Satellite retrieval of convective cloud base temperature based on the NPP/VIIRS Imager, Geophys. Res. Lett., 41, 1308-1313, 2014.

Zhu, Y., Rosenfeld, D., and Li, Z.: Under what conditions can we trust retrieved cloud drop concentrations in broken marine stratocumulus?, J. Geophys. Res.-Atmos., 123, 8754-8767, 2018.

Zuidema, P., Painemal, D., De Szoeke, S., and Fairall, C.: Stratocumulus Cloud-Top Height Estimates and Their Climatic Implications, J. Climate, 22, 4652-4666, 2009. 